\title{
Experimental investigation of the effect of transpiration cooling on second mode instabilities in a hypersonic boundary layer
}

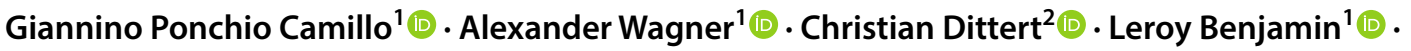 \\ Viola Wartemann ${ }^{3}$ (D) Jens Neumann ${ }^{3} \cdot$ Rüdiger Hink ${ }^{3}$
}

Received: 20 December 2019 / Revised: 19 April 2020 / Accepted: 10 June 2020 / Published online: 27 June 2020

(c) The Author(s) 2020

\begin{abstract}
The influence of localized nitrogen transpiration on second mode instabilities in a hypersonic boundary layer is experimentally investigated. The study is conducted using a $7^{\circ}$ half-angle cone with a length of $1100 \mathrm{~mm}$ and small nose bluntness at $0^{\circ}$ angle-of-attack. Transpiration is realized through a porous Carbon/Carbon patch of $44 \times 82 \mathrm{~mm}$ located near the expected boundary layer transition onset location. Transpiration mass flow rates in the range of $0.05-1 \%$ of the equivalent boundary layer edge mass flow rate were used. Experiments were conducted in the High Enthalpy Shock Tunnel Göttingen (HEG) at total enthalpies around $3 \mathrm{MJ} / \mathrm{kg}$ and unit Reynolds numbers in the range of $1.4 \cdot 10^{6}$ to $6.4 \cdot 10^{6} \mathrm{~m}^{-1}$. Measurements were conducted by means of coaxial thermocouples, Atomic Layer Thermopiles (ALTP), pressure transducers and high-speed schlieren. The present study shows that the most amplified second mode frequencies were shifted to lower values as nitrogen is transpired into the boundary layer. In some cases the instability amplitudes were found to be significantly reduced. The observed frequency reduction was verified to correlate with the change of the relative sonic line height in the boundary layer. The amplitude damping was observed to occur only until the most amplified frequencies were reduced to around 50\% of their undisturbed values. When transpiration within this limit was performed shortly upstream of the natural boundary layer transition onset, a transition delay of approximately $17 \%$ could be observed.
\end{abstract}

Giannino Ponchio Camillo

Giannino.PonchioCamillo@dlr.de

Alexander Wagner

Alexander.Wagner@dlr.de

1 German Aerospace Center (DLR), Institute of Aerodynamics and Flow Technology, Göttingen, Germany

2 German Aerospace Center (DLR), Institute of Structures and Design, Stuttgart, Germany

3 German Aerospace Center (DLR), Institute of Aerodynamics and Flow Technology, Braunschweig, Germany 


\section{Graphic abstract}
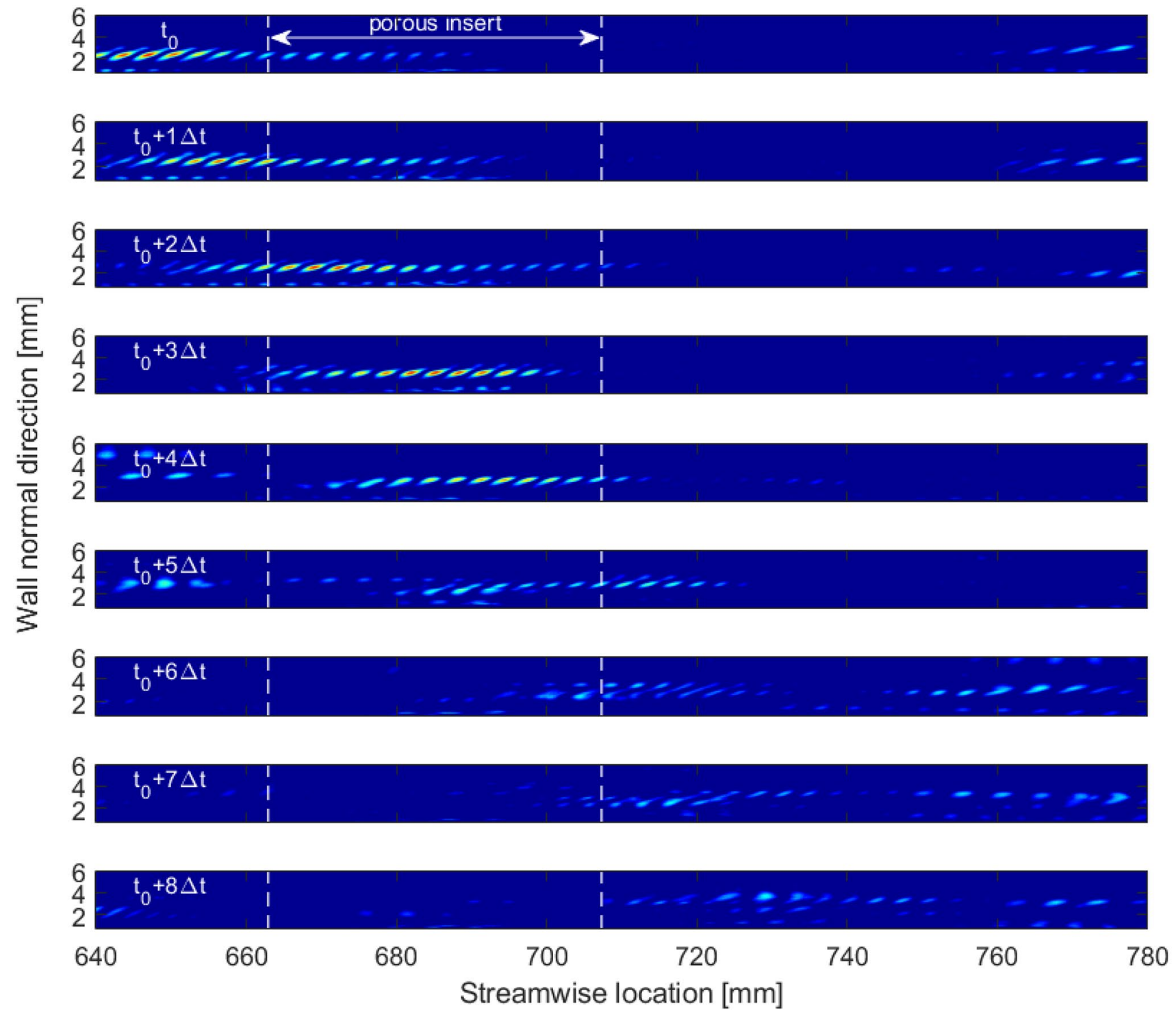

\section{Introduction}

The understanding of the boundary layer transition process in supersonic and hypersonic boundary layers is crucial for the optimized design of vehicles operating at such speeds. Uncertainties in the transition location prediction directly lead to uncertainties in the estimated viscous drag and the surface heat flux, which are both essential design parameters for vehicles operating in hypersonic conditions.

Mass addition into a boundary layer through porous surfaces in hypersonic flow has been used in the past in experimental investigations in the 1960s and 1970s to simulate the ablation effect of thermal protection systems. For these investigations, conical shapes were frequently used, and many different gases were transpired at various flow conditions and locations. It was noticed by many authors that the transpiration of gas into a boundary layer also played an important role on its stability, potentially affecting the location of boundary layer transition.

The effects of air and helium transpiration into a conical boundary layer near the tip at Mach 10 were experimentally investigated by Dunavant and Everhart (1969). Early boundary layer transition was observed with helium when transpiration was close to the natural transition location, and for all 
cases with air. Marvin and Akin (1970) observed decreasing transition Reynolds numbers while increasing the injection rate of air, helium or argon through an extensive porous surface on a conical body at a free-stream Mach number of 7.4. The observations were confirmed by Laganelli et al. (1975) injecting air into a conical boundary layer at Mach 7.9.

A comprehensive review of these and several other early efforts was presented by Schneider (2010), highlighting investigations that yielded information on the effects of mass transpiration on the boundary layer stability. It was observed that, in general, boundary layer transition moved upstream with mass addition, and the effect was pronounced for higher mass flow rates and lighter gases.

However, recent investigations indicated that this earlyestablished general rule may not hold for all cases in which second mode waves dominate the transition process. Fujii and Hornung (2003) highlighted the potential of $\mathrm{CO}_{2}$ on damping acoustic disturbances such as the second modes in high-enthalpy flows. Wagnild et al. (2010) used Parabolized Stability Equations (PSE) to assess the stabilizing effects of transpiring $\mathrm{CO}_{2}$ through a short-length porous surface into the boundary layer of a sharp cone at high-enthalpy free-stream conditions. Competing effects were observed between the stabilizing characteristics of $\mathrm{CO}_{2}$, which were mainly but not exclusively due to vibrational relaxation, and the destabilizing due to blowing, which was consistently reported in earlier works. The experimental results obtained at similar conditions in Jewell et al. (2012) showed a delay of transition caused be the injection of $\mathrm{CO}_{2}$, contradicting the observations in Wagnild et al. (2010).

Interestingly, the $\mathrm{N}$-factor envelope obtained numerically by Wagnild et al. (2010) revealed the $\mathrm{N}$-factor maximum to be right downstream of the injection. Further downstream a stabilization region followed by a steep rise of the $\mathrm{N}$-factor was observed. Fedorov et al. (2014), provided a detailed analysis using Linear Stability Theory (LST) to study the effects of transpired air instead of $\mathrm{CO}_{2}$ at the same freestream conditions to isolate the injection effect from the stabilizing effects of $\mathrm{CO}_{2}$. It was found that with injection, the maximal growth rates of the most unstable frequencies increased, causing the before mentioned local maximum in $\mathrm{N}$-factor immediately after injection. However, the width of the unstable region for each frequency was reduced leading to a reduction of the cumulative $\mathrm{N}$-factor downstream. The steep rise of the $\mathrm{N}$-factor following further downstream was found to be due to the overlap of multiple unstable frequencies.

These results suggest an explanation why early investigations consistently observed a negative effect of transpiration on the boundary layer stability. Namely, mass addition in those studies was performed along a large portion of the body. At the same time, the numerical observations also indicate that mass addition in a limited section slows down second mode instability growth. This means that a localized mass addition might be able to detune the boundary layer with respect to the most amplified second mode frequencies such that transition delay is achieved.

Nonetheless, the complexity of the interactions between the injected gas and the boundary layer may also cause the transition mechanism to change. Li et al. (2011) and Li et al. (2013), used both PSE and quasi-parallel stability theory to analyze the stability of a low-enthalpy supersonic conical boundary layer at a free-stream Mach number of 7.4 with a large transpiration surface. The results showed not only a reduction of the second mode peak frequency but also an overall stabilization of these modes. As a possible explanation for the disagreement between the numerical results and the consolidated experimental trends at similar, large-surface transpiration conditions in the literature, it was suggested that an absolutely unstable, wall bounded mixing layer could be the key mechanism of transition in this case, instead of second modes. With a different approach, the Kelvin-Helmholtz instability of free shear layers was hypothesized as dominant mechanism in Schmidt and Shepherd (2016), where the effects of transpiring gases with different molecular masses through a short porous section were investigated. Results showed transition onset to monotonically shift upstream as the injection gas was lighter and the mass flow rate was higher, while observations with schlieren imaging showed little variation of second mode characteristics.

While conclusions regarding the boundary layer stability effects of mass addition are still disputed, Fig. 1 shows that a very wide and diverse range of conditions was covered in the literature so far. The figure presents a non-exhaustive, simplified compilation of transpiration conditions studied by several authors, in the form of non-dimensional mass flow rate as a function of local length Reynolds number, evaluated along the transpiration region of each investigation. All mass flow rates are presented in the same normalization, which is provided in detail in this work. To allow a direct comparison between the different studies the local Reynolds numbers are evaluated along the surface of the wind tunnel model using the boundary layer edge properties. The latter are obtained by converting the free-stream conditions provided by the authors, to boundary layer edge conditions using the Taylor-Maccoll conical shock relations and assuming a power law for the viscosity.

In the figure, the dashed lines denote studies conducted with transpiration gases other than air or nitrogen. While most of the plotted studies were conducted with total temperatures around or below $1000 \mathrm{~K}$, Wagnild et al. (2010) and Fedorov et al. (2014) used high enthalpy test conditions with total temperatures around $5800 \mathrm{~K}$. In the present work, free-stream conditions with total temperatures of around $2800 \mathrm{~K}$ were used. 
Fig. 1 Non-dimensional transpiration mass flow rate as a function of the boundary layer edge Reynolds number based on the transpiration location, as investigated by several authors. Dashed boxes denote studies with gases other than air or nitrogen. Abbreviations: Pp: Pappas and Okuno (1964), Dn: Dunavant and Everhart (1969), Mv: Marvin and Akin (1970), Mt: Martelucci (1972), Lg: Laganelli et al. (1975), Jh: Johnson et al. (2009), Wg: Wagnild et al. (2010), Gl: Gülhan and Braun (2011), Li: Li et al. (2013), Fd: Fedorov et al. (2014), Sa: Schmidt et al. (2016), Sb: Schmidt and Shepherd (2016), Mr: Miró Miró et al. (2019)

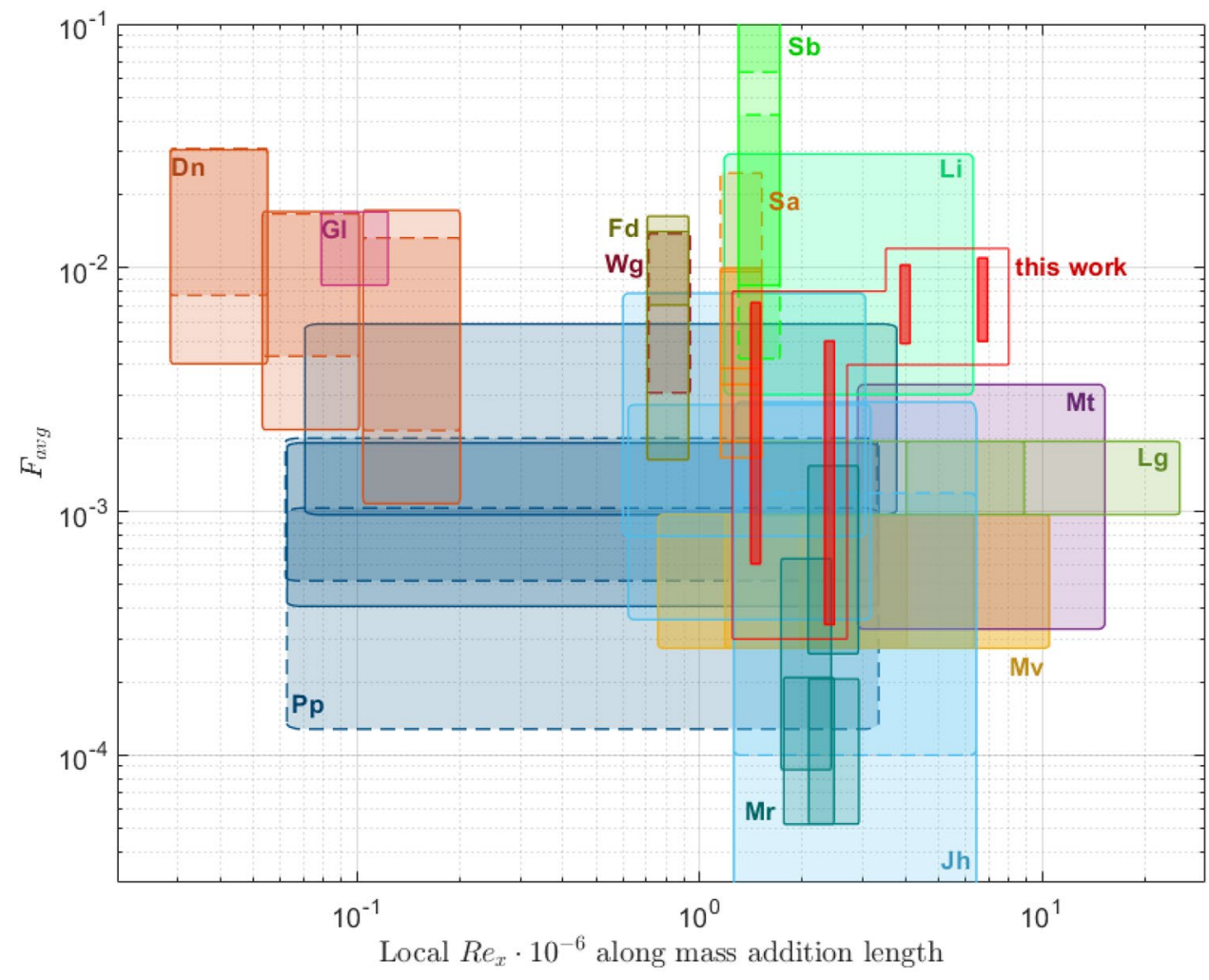

This work presents results of experimental studies on the effect of nitrogen transpiration into a conical, supersonic boundary layer. Mass addition is realized through a Carbon/ Carbon (C/C) porous ceramic material (Wagner et al. 2014; Dittert et al. 2015) of short streamwise length. The possibility of detuning the boundary layer with respect to the most unstable second mode instabilities and thus delaying boundary layer transition by means of localized mass addition is investigated.

\section{Experimental setup}

\subsection{The High Enthalpy Shock Tunnel Göttingen}

The experimental results presented in this paper were obtained in the High Enthalpy Shock Tunnel Göttingen (HEG) which is a free-piston driven reflected shock tunnel. It provides a pulse of gas to a hypersonic nozzle at stagnation pressures of up to $200 \mathrm{MPa}$ and stagnation enthalpies of up to $25 \mathrm{MJ} / \mathrm{kg}$ (Eitelberg et al. 1992; Eitelberg 1994). Its range of operating conditions was successively extended to allow investigations of the flow past hypersonic flight configurations from low altitude Mach 6 up to Mach 10 at approximately $33 \mathrm{~km}$ altitude (DLR 2018). In the present study HEG was operated at Mach 7.4 using a nozzle exit diameter of $0.59 \mathrm{~m}$ and an expansion ratio of 218 .
The test conditions used are listed in Table 1. The stagnation values in the table correspond to the average properties of all corresponding runs considered for this work, with their respective standard deviations in parenthesis. The values at the nozzle exit are obtained through a calibration procedure which is described in detail in DLR (2018). The gas at the nozzle exit is found to be in thermal and chemical equilibrium. Test times are typically around $3 \mathrm{~ms}$.

Table 1 HEG free-stream conditions of the present study. Stagnation conditions are averages of all corresponding runs used in this work, with associated standard deviations. Static conditions are provided at the nozzle exit using the averaged reservoir conditions

\begin{tabular}{lllll}
\hline Condition & A & B & C & $\mathrm{D}$ \\
\hline$p_{0}[\mathrm{MPa}]$ & $6.6(4.5 \%)$ & $11.6(1.5 \%)$ & $18.7(2.7 \%)$ & $29.3(1.4 \%)$ \\
$T_{0}[\mathrm{~K}]$ & $2744(1.7 \%)$ & $2848(0.8 \%)$ & $2761(1.8 \%)$ & $2621(0.4 \%)$ \\
$h_{0}[\mathrm{MJ} / \mathrm{kg}]$ & $3.24(2.2 \%)$ & $3.41(1.0 \%)$ & $3.28(2.3 \%)$ & $3.08(0.5 \%)$ \\
$M_{\infty}[-]$ & 7.3 & 7.3 & 7.4 & 7.4 \\
$R e_{m}\left[\mathrm{~m}^{-1}\right]$ & $1.4 \cdot 10^{6}$ & $2.3 \cdot 10^{6}$ & $3.8 \cdot 10^{6}$ & $6.4 \cdot 10^{6}$ \\
$p_{\infty}[\mathrm{Pa}]$ & 770 & 1330 & 2100 & 3190 \\
$T_{\infty}[\mathrm{K}]$ & 274 & 287 & 273 & 253 \\
$\rho_{\infty}\left[\mathrm{g} / \mathrm{m}^{3}\right]$ & 9.7 & 16.2 & 26.7 & 43.8 \\
$u_{\infty}[\mathrm{m} / \mathrm{s}]$ & 2450 & 2480 & 2440 & 2370 \\
\hline
\end{tabular}



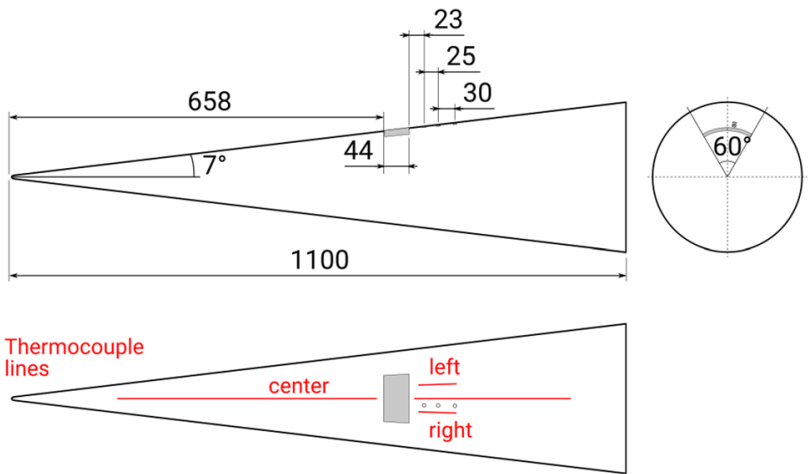

Fig. 2 Schematic of the cone model used in the present study. The porous insert is depicted in gray. The ALTP sensor positions are indicated immediately downstream of the insert. The red lines illustrate the locations of the thermocouples. Dimensions in millimeters

\subsection{Wind tunnel model and instrumentation}

The investigated model is a $7^{\circ}$ half-angle cone at $0^{\circ}$ angle-ofattack with a $44 \times 82 \mathrm{~mm}$ (streamwise $\times$ spanwise) porous $\mathrm{C} / \mathrm{C}$ insert with constant $10 \mathrm{~mm}$ thickness designed for transpiration cooling, starting $658 \mathrm{~mm}$ from the cone tip, as shown in Fig. 2. An exchangeable tip allowed investigating three different nose radii, namely $5 \mathrm{~mm}, 2.5 \mathrm{~mm}$ and 0.1 $\mathrm{mm}$. The cone was mounted in the test section such that line-of-sight schlieren visualization around the region of transpiration and further downstream was facilitated. At this position the cone partly reached into the contoured nozzle.

By varying both the free-stream unit Reynolds number and the model nose radius, a wide range of boundary layer transition locations, with respect to the transpiration insert were realized. Figure 3 shows representative normalized surface heat flux distributions obtained in the present study without gas transpiration. Free-stream conditions are represented as colors, and nose radii as symbols. The porous insert location is also shown for reference. The correlation between transition onset location, unit Reynolds number and the cone tip radius is depicted. Thus, the variable transition locations on the cone allowed investigating the effects of local mass addition on boundary layers at different transitional states.

Lines of Medtherm coaxial Type E thermocouples distributed along two generatrices of the cone were used to monitor boundary-layer transition by means of surface heat flux measurements. On the opposite side of the porous patch, a line of approximately uniformly spaced thermocouples provided repeatable reference measurements in each run. On the porous patch side, thermocouples were installed along a streamline crossing its center, with increased spatial resolution downstream of the transpiration location. Two shorter lines of thermocouples were positioned downstream of the porous insert on the left and the right of the center line, to

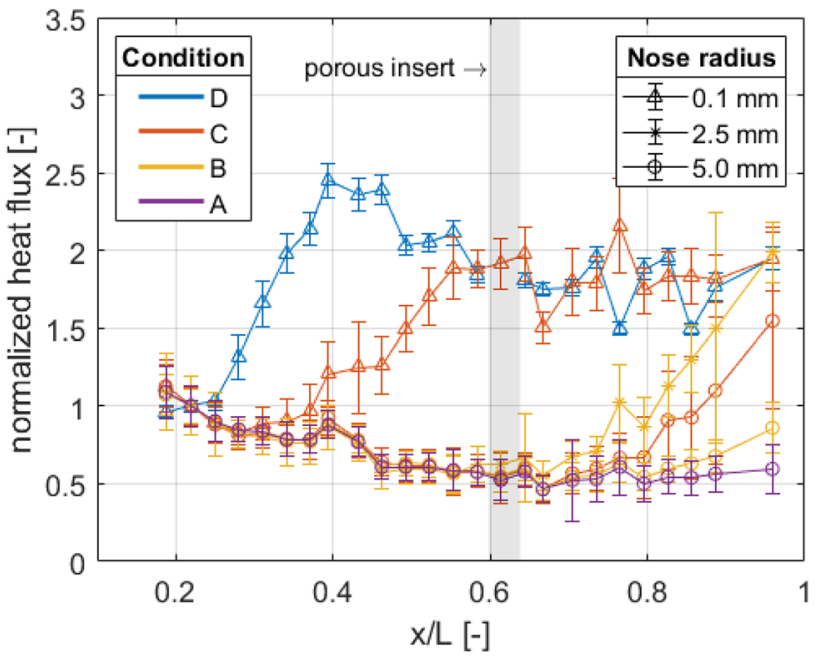

Fig. 3 Normalized surface heat flux distribution along the cone axis without transpiration, for various free-stream conditions and nose radii. Surface heat fluxes are normalized with the laminar heat flux level of each test condition measured at $242 \mathrm{~mm}$. The grey column indicates the position of the porous sample

monitor potential effects caused by the finite width of the injection patch. The locations of these thermocouple lines are illustrated in Fig. 2.

Four pairs of GE NPP-301 and Kulite XCEL-100 pressure transducers were installed in radially opposing positions in different sections of the model to monitor the angle-ofattack and yaw angle of the model. Two additional GE NPP301 pressure transducers in the plenum chamber below the porous surface monitored the plenum pressure during the tests. The mass flow rate of nitrogen into the plenum was monitored using a MKS Instruments $\mathrm{GmbH}$ digital mass flow monitor of type 579A.

Three Atomic Layer Thermopiles transducers of type FOR-ALTP 2.5/1/100DYN-CAL were installed 23, 48 and $78 \mathrm{~mm}$ downstream of the porous insert offering high-frequency heat flux information. The transducers have an active area of $2.5 \times 1 \mathrm{~mm}$ (width $\times$ length), a response time of less than $1 \mu s$ and a bandwidth of $17 \mathrm{~Hz}$ to $1 \mathrm{MHz}$ with $-3 \mathrm{~dB}$. Due to the large uncertainty of the nominal ALTP sensitivity of around 25\%, an in-situ calibration of the ALTP DC output against Medtherm thermocouples readings was conducted yielding sensitivities in the range of 35-50 $\mu V /\left(W / \mathrm{cm}^{2}\right)$.

All transducer signals were recorded using Amotronic transient recorders, with sampling rates of $1 \mathrm{MHz}$ for the thermocouples and up to $10 \mathrm{MHz}$ for the ALTPs, depending on the test conditions. If present, sharp peaks due to electrical noise were filtered out from the ALTPs timeseries using second-order IIR bandstop filters.

Heat flux spectral information were obtained as amplitude spectral densities (ASD) using Welch's average estimator. The time series recorded by the ALTPs during steady-state 
time were processed using Hamming windowed segments of 2048 samples each and $40 \%$ overlap.

The Z-type high-speed schlieren used a Phantom v2012 camera, driven by a Cavilux laser source. Frames were recorded at $170 \mathrm{kHz}$ with a resolution of either $1024 \times 112$ or $1280 \times 96$ pixels. This yielded a spatial resolution of $0.14 \mathrm{~mm} / \mathrm{pixel}$, while the undisturbed second modes were expected to have a wavelength of around $6.5 \mathrm{~mm}$. The camera was tilted by 7 degrees to match the inclination of the cone surface. The knife edge was oriented horizontally. The images were post-processed following Petervari (2014) and Benjamin (2017) to extract information on second modes such as convection speed and frequency.

\section{Numeric methods}

\subsection{Mean flow solver}

The DLR TAU code is used for all base flow computations. The code is a three-dimensional parallel hybrid multi-grid code and has been validated for hypersonic flows (see e.g. Mack and Hannemann 2002, Schwamborn et al. 2006 or Reimann and Hannemann 2010). The calculations, including the expansion process through the nozzle and the mass injection on the cone, are conducted using non-equilibrium gas modelling with 5 species for air: $\mathrm{N}_{2}, \mathrm{O}_{2}, \mathrm{NO}, \mathrm{N}, \mathrm{O}$ in combination with thermal equilibrium and chemical nonequilibrium (one temperature model), which was shown to be a suitable approach for the test conditions investigated previously (Wartemann et al. 2019c; DLR 2018). The transport coefficients are expressed in terms of collision integrals (Bottin 1999). The mixing rules are based on constant Schmidt numbers. Further, lookup tables are used, see Esser (1991). Axisymmetric grids are applied. Previous analyses have shown that the base flow simulations should include the nozzle, test chamber, and cone model itself (Wartemann et al. 2019c), which is consequently applied in this paper. For all grids, grid refinement towards the walls as well as around the shock is applied. A grid study can be found in Wartemann et al. (2019c). Based on the nozzle calibration of Wagner (2014), the nozzle boundary-layer is set turbulent, which is modelled with the Spalart-Allmaras turbulence model. The model wall temperature for all tests is assumed to be isothermal at $293 \mathrm{~K}$. This temperature is also applied for the gas injected into the boundary layer. Air is used as transpired gas after a cross-check for selected cases with nitrogen yielded good agreement, thus, complementing previous studies presented in Wartemann et al. (2019a). Instead of a complete simulation of the mass flow through the porous ceramic, a mass flow wall condition is applied.
A detailed description of this wall condition for the effusion section can be found in Hannemann (2006).

\subsection{Stability code}

For the stability analyses the NOLOT code (NOnLocal Transition analysis, Hein et al. 1994) is used. NOLOT was developed in cooperation between DLR and the Swedish Defence Research Agency (FOI) and can be used for local as well as non-local spatial analyses. The equations are derived from the conservation equations of mass, momentum and energy, which govern the flow of a viscous, compressible, ideal gas. All flow and material quantities are decomposed into a steady laminar base flow $\bar{q}$ and an unsteady disturbance flow $\tilde{q}$ :

$q\left(x_{c}, y_{c}, z_{c}, t\right)=\bar{q}\left(x_{c}, y_{c}\right)+\tilde{q}\left(x_{c}, y_{c}, z_{c}, t\right)$.

The laminar base-flow $\bar{q}$ is calculated by the DLR TAU code (see previous Sect. 3.1). The disturbance $\tilde{q}$ of Eq. (1) is represented as a harmonic wave:

$\tilde{q}\left(x_{c}, y_{c}, z_{c}, t\right)=\hat{q}\left(x_{c}, y_{c}, z_{c}\right) \exp \left[i\left(\alpha x_{c}+\beta z_{c}-\omega t\right)\right]$

with the complex-valued amplitude function $\hat{q}$. The three coordinate directions of the equations 1 and 2 are denoted as $x_{c}, y_{c}$ and $z_{c}$ and describe a curvilinear surface-oriented orthogonal coordinate system. Previous investigations of the same geometry with similar free-stream conditions, including different mass fluxes, show that the differences between Linear Stability Theory (LST) and Parabolized Stability Equations (PSE) are negligible (Wartemann et al. 2019a). Consequently, the local-parallel LST approach is applied for the investigations of this paper. Currently, the NOLOT stability code is limited to perfect-gas assumptions (calorically or/and thermally perfect). For low-enthalpy cases such as those investigated in this paper, it is possible to neglect real-gas effects for the stability calculation, as long as they are included in the base flow calculations (Wartemann et al. 2019c).

\section{Gas injection into the boundary layer}

\subsection{Porous patch characterization}

In the present work, mass addition into the boundary layer is achieved through a $\mathrm{C} / \mathrm{C}$ porous patch. The dependency between the velocity of a fluid through a porous medium and the pressure gradient across the medium can be described using the Darcy-Forchheimer law, Eq. (3). In this equation, $k_{D}$ and $k_{F}$ are permeability coefficients which account for the viscous and inertial contributions, $P$ is the pressure, $v$ the fluid velocity, $\mu$ its viscosity and $\rho$ its density. It will be shown that 
for the range of mass flow rates investigated here, the inertial term cannot be neglected.

$-\Delta P=\frac{\mu v}{k_{D}}+\frac{\rho v^{2}}{k_{F}}$

This equation may be worked into a more practical form with a few considerations.

The transpired gas is assumed to be an ideal gas at constant temperature. The pressure gradient across the porous material is assumed to be large enough to consider the external pressure to be negligible. The latter assumption holds since the pressures needed to realize the present mass flow rates are at least one order of magnitude higher than the model surface pressure during a test.

The porous patch was machined from a $\mathrm{C} / \mathrm{C}$ block such that its outer shape fits the cone contour. However, the main orientation of the pores between the parallel $\mathrm{C} / \mathrm{C}$ layers was uniform, as shown in Fig. 4. Hence in this study the flow through the porous patch is approximated as planar, rather than radial as in Schmidt et al. (2016). Mass flux in the direction perpendicular to the orientation of the pores is neglected, since the material is anisotropic and permeability is considerably larger in the direction of the pores (Dittert et al. 2015).

Finally, due to the parallel fiber orientation and the uniform pressure distribution provided in the plenum chamber below the patch, the mass transpiration is assumed to be uniform along the dimensions of the insert, as seen in Dittert et al. (2015)

With the above assumptions, Eq. (3) yields:

$P_{p}^{2}=2 t R T_{p}\left(\frac{\mu_{p} \dot{m}}{A k_{D}}+\frac{\dot{m}^{2}}{A^{2} k_{F}}\right)$

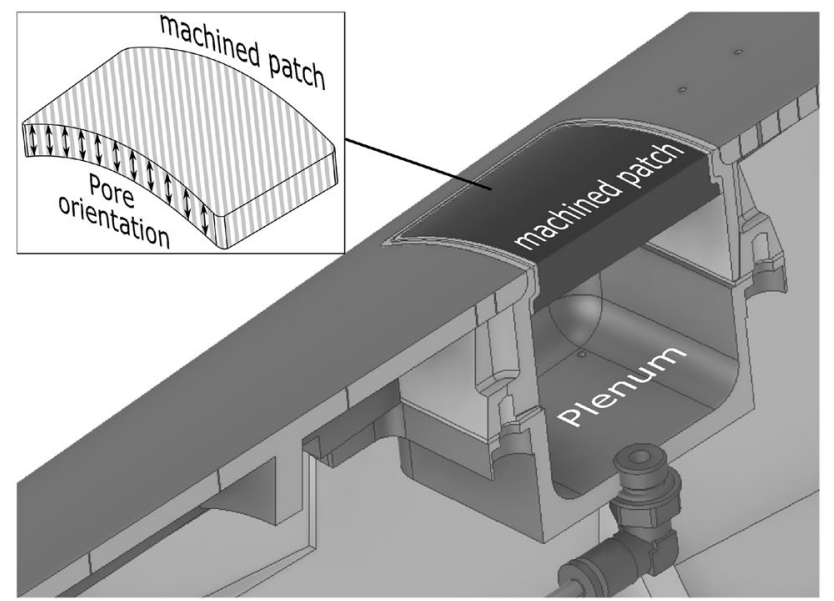

Fig. 4 Cut view through the $\mathrm{C} / \mathrm{C}$ porous patch and the plenum chamber below. The detail shows the uniform pore orientation of the machined porous patch where the subscript $p$ refers to values in the plenum, $\dot{m}$ is the mass flow rate, $T$ the temperature of the injected gas, $R$ the gas constant, $A$ the surface area of the porous patch and $t$ its thickness.

The permeability of the porous insert is determined experimentally by applying constant pressure in the plenum below the porous patch and measuring the mass flow rate simultaneously. The best fit of the coefficients $k_{D}$ and $k_{F}$ are calculated using a least square fit. Figure 5 shows the observed dependency between plenum pressure and mass flow rate. The resulting fit is plotted as solid line and yields permeability values of $k_{D}=5.547 \cdot 10^{-13} \mathrm{~m}^{2}$ and $k_{F}=2.104 \cdot 10^{-7} \mathrm{~m}$. The dotted lines show a $95 \%$ confidence interval of the fit.

Figure 5 also shows as a dash-dot line the result of applying Darcy's law considering only the $k_{D}$ contribution in Eq. (4) as often proposed in the literature. The differences are small for low mass flow rates, but increase with increasing plenum pressure. This evidences the relevance of the second term in the present case.

Potential roughness effects caused by the porous patch were analyzed comparing the measured heat flux distributions on both sides of the cone, without mass transpiration. No significant differences on the boundary layer transition onset were observed. Thus, roughness effects due to the porous patch are neglected in the present study.

\subsection{Transpiration procedure}

To allow a controlled and predictable mass addition into the boundary layer, the model was designed with a plenum below the porous insert, as seen in Fig. 4. Due to the short

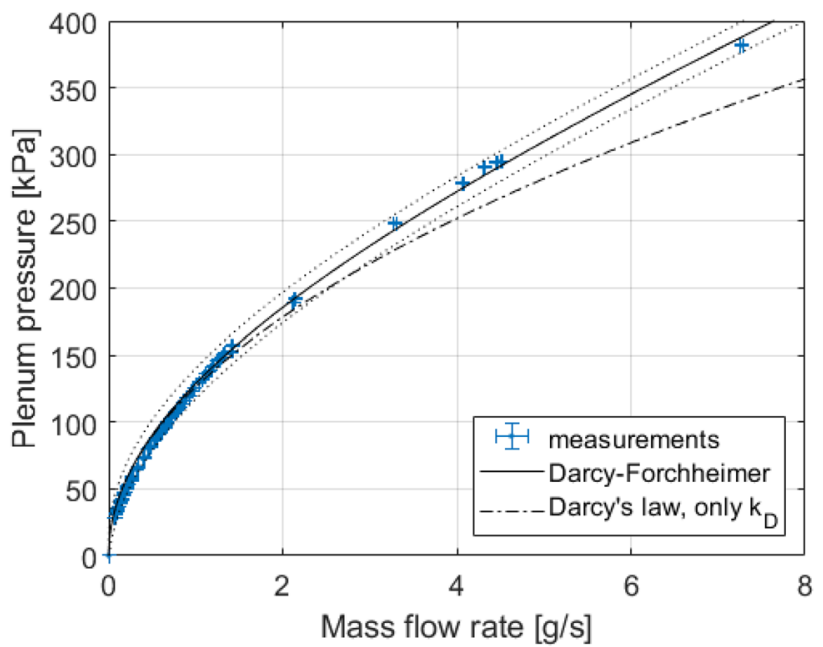

Fig. 5 Mass flow rate through the porous patch as function of plenum pressure. A least-squares fit using Darcy-Forchheimer's law is shown as a solid line. Darcy's law neglecting the inertial term is plotted as a dash-dot line 
test times the plenum was pressurized with nitrogen already before the test in HEG to ensure steady-state injection conditions. This was particularly important for low mass flow rates.

Both the mass flow rate and the pressure readings in the plenum were recorded for each run. Figure 6 shows examples of the recorded values for three runs with condition B and nose radius $5.0 \mathrm{~mm}$. They are representative for low, medium and high mass flow rates in the context of the present study. The local surface pressures obtained by a transducer in the vicinity of the patch are shown as well. All three cases show similar features, with flow arrival at around $1 \mathrm{~ms}$ and steady-state times from roughly 3 to $6 \mathrm{~ms}$. No significant changes of the mass flow rate and the plenum pressure are observed in the test time. This observation supports the assumption made for Eq. (4), i.e. assuming the external pressure to be negligible. Furthermore, the plenum pressure was verified not to show a significant increase for cases with no transpiration.
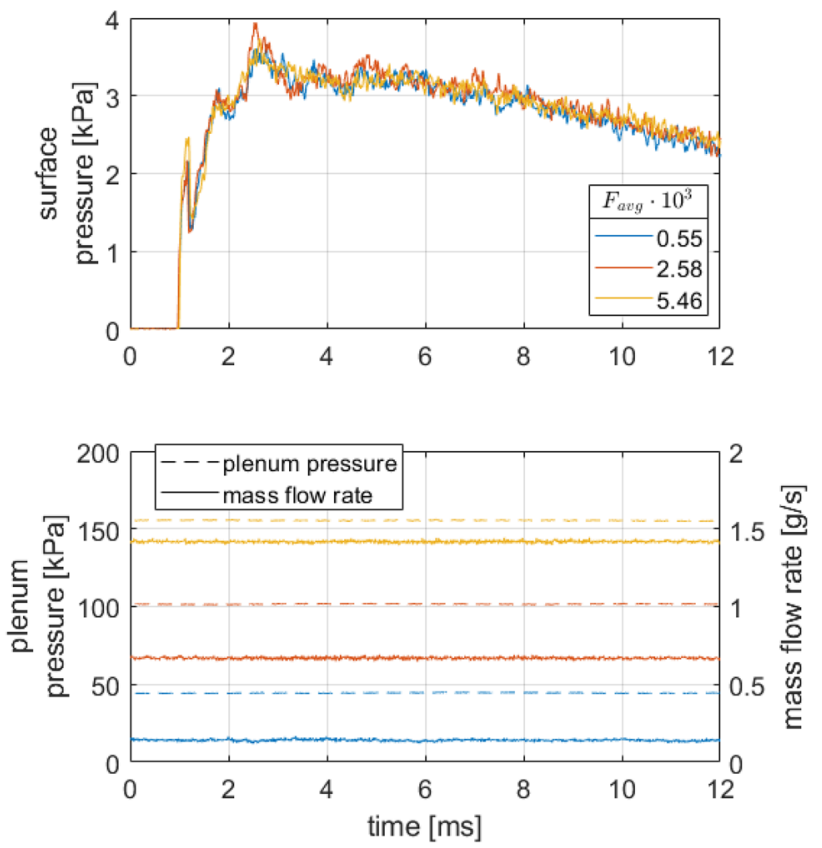

Fig. 6 Representative mass flow rates, plenum pressures and local surface pressures for test condition $\mathrm{B}$, nose radius $5.0 \mathrm{~mm}$
All mass flow rates investigated here and the corresponding test conditions are provided in Table 2.

\subsection{Assessment of boundary layer transition onset}

In the course of the analyses presented in the results section of this paper, it will be necessary to define the location of boundary layer transition. This will be assessed by means of heat flux distribution on the cone surface, measured by the line of thermocouples crossing the center of the porous insert. Transition onset is assumed to happen at the location where the heat flux distribution stops following the laminar level and starts increasing towards the turbulent level.

Extra considerations are necessary in the cases analyzed in this work, since the cold gas transpiration also affects the heat flux measurements due to cooling effects. To prevent this from biasing the results, CFD quantities obtained for a laminar boundary layer without transpiration are used as an auxiliary parameter. The transition onset location is estimated based on the intersection between the numerical laminar prediction and a linear fit through the transitional portion of the measured data. Figure 7 shows an example of

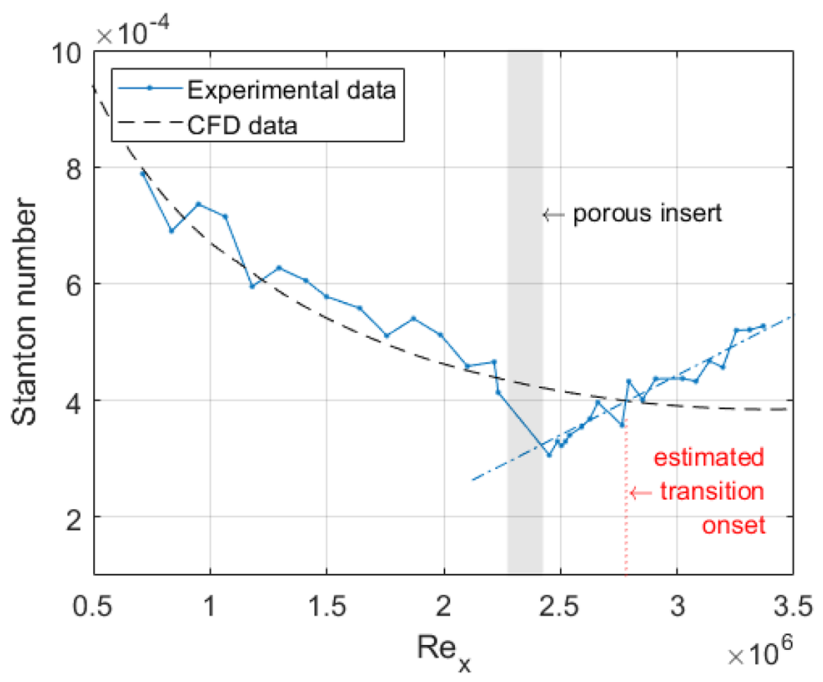

Fig. 7 Example of estimation of boundary layer transition onset location, shown for test condition $B$, nose radius $5.0 \mathrm{~mm}$ and $F_{\text {avg }}=0.83 \cdot 10^{-3}$
Table 2 Transpiration mass flow rates and corresponding test conditions investigated in the present study

\begin{tabular}{llll}
\hline Cond. & $R_{\text {nose }}[\mathrm{mm}]$ & $\dot{m}[\mathrm{~g} / \mathrm{s}]$ & $F_{\text {avg }} \cdot 10^{3}$ \\
\hline A & 5.0 & $0,0.1,0.25,0.4,0.65,0.82,1.15$ & $0,0.56,1.74,2.64,4.25,5.44,7.55$ \\
B & 2.5 & $0,0.12,0.18,0.26$ & $0,0.45,0.71,1.01$ \\
B & 5.0 & $0,0.14,0.22,0.42,0.67,0.85,1.4$ & $0,0.55,0.83,1.60,2.58,3.28,5.46$ \\
C & 0.1 & $0,2.1,4.5$ & $0,4.97,10.45$ \\
C & 5.0 & $0,4.0$ & $0,9.26$ \\
D & 0.1 & $0,3.3,7.3$ & $0,4.95,10.94$ \\
\hline
\end{tabular}


this approach, with the resulting estimated transition onset location highlighted.

\section{Results}

The results are distinguished in sets of cases with fully turbulent or fully laminar boundary layer at the location of transpiration, as shown in Fig. 3 in Sect. 2.

To denote streamwise location, the length Reynolds number using boundary layer edge conditions is used. The boundary layer edge conditions are calculated based on freestream properties using the Taylor-Maccoll solution for inviscid supersonic flow over a cone. Viscous effects and the influence of the nose radius on the boundary layer edge conditions are neglected due to the large distance between the porous patch and the nose of the cone. Comparisons between the Taylor-Maccoll solution and the static pressure in the vicinity of the porous patch calculated with CFD yielded maximum differences of around $5 \%$.

Time averaged surface heat flux is normalized according to the Stanton number definition, Van Driest (1956). Finally, the transpiration mass flow rates are normalized according to Eq. (5), as used in Pappas and Okuno (1964) and Johnson et al. (2009).

$F_{\text {avg }}=\frac{(\rho u)_{w}}{(\rho u)_{e}}$

where $\rho$ is the density, $u$ the velocity, and the subscripts $w$ and $e$ indicate conditions at the wall and boundary layer edge, respectively. The wall conditions are obtained by the mass flow rate through the porous insert measured during the tests, divided by the insert surface area. The boundary layer edge values are obtained from the inviscid solution, as mentioned before.

\subsection{Gas injection in turbulent boundary layers}

Fully turbulent conditions at the location of the porous surface are obtained with conditions $\mathrm{C}$ and $\mathrm{D}$, and $0.1 \mathrm{~mm}$ nose tip. Figures 8 and 9 show the averaged Stanton numbers for different mass transpiration rates for these conditions, obtained from the thermocouples along the transpiration side of the cone. In these figures, the position of the three ALTP sensors and the location of the porous surface are shown, for reference. The numerical laminar and turbulent Stanton number distributions are depicted as dashed and dashed-dot lines, respectively.

Figures 8 and 9 show that for both sets of cases there is a clear cooling effect resulting from the transpiration of nitrogen, with decreasing surface heat flux as the mass flow rates increase. Immediately following transpiration, a reduction

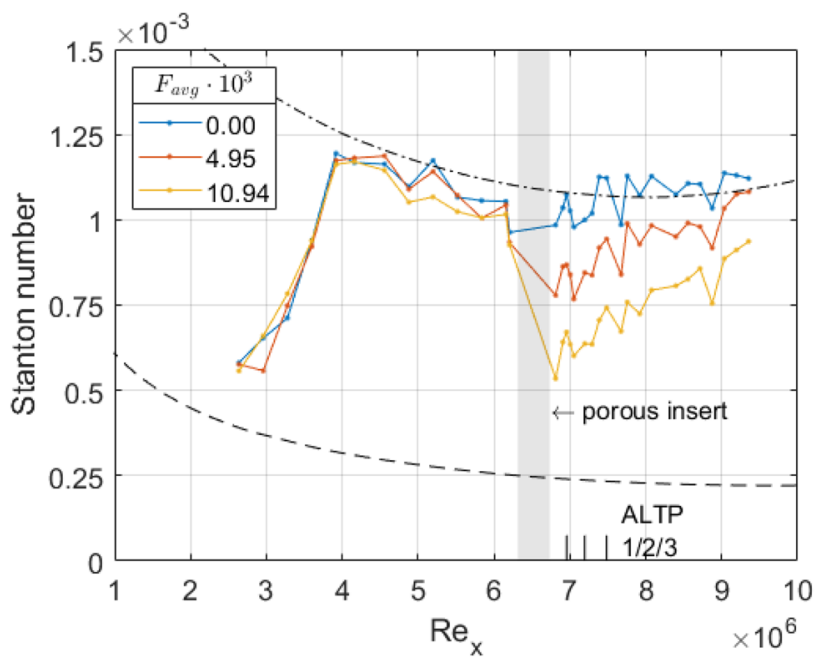

Fig. 8 Stanton number distribution as a function of local Reynolds number along the cone axis for $0.1 \mathrm{~mm}$ nose radius, test condition D and different transpiration rates

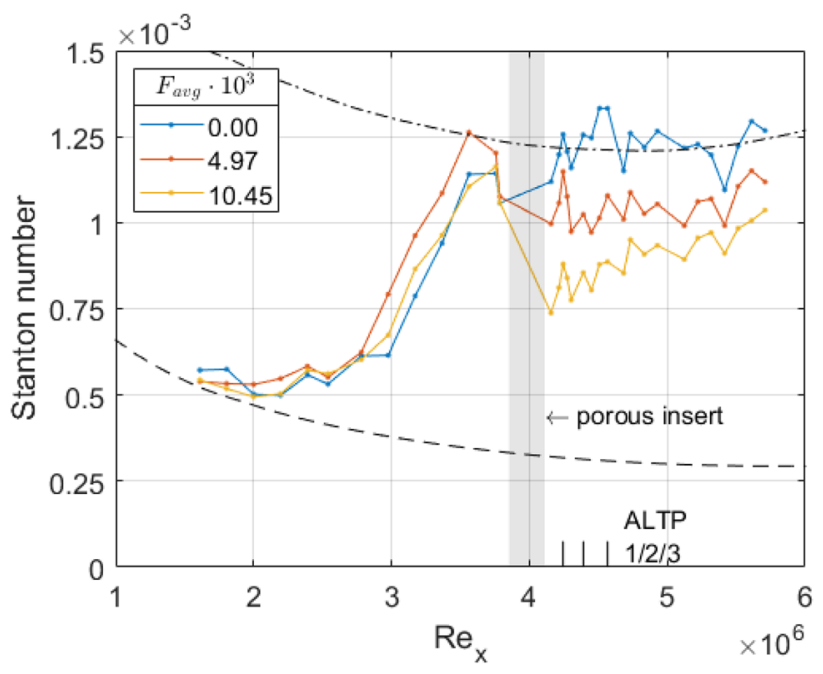

Fig. 9 Stanton number distribution as a function of local Reynolds number along the cone axis for $0.1 \mathrm{~mm}$ nose radius, test condition $\mathrm{C}$ and different transpiration rates

in Stanton number values of up to $40 \%$ is achieved. As the cooling effect diminishes, the Stanton number reduction is still as high as $18 \%$ on the most downstream measurement on the cone compared to the test case without transpiration. On one hand, this represents an overall heat flux reduction of $30 \%$ on the cone surface downstream of the transpiration location. On the other hand, however, the heat fluxes are still higher compared to a fully laminar case, meaning an action towards preventing boundary layer transition is still more advantageous. Furthermore, the transpiration mass flow rates necessary for observing such cooling effect on the turbulent 
boundary layer are an order of magnitude larger than the flow rates used in the present study to modify the second mode development.

\subsection{Gas injection in laminar boundary layers}

With a $5 \mathrm{~mm}$ nose radius, the boundary layer is entirely laminar along the cone length for a unit Reynolds number of $1.4 \cdot 10^{6} \mathrm{~m}^{-1}$ (condition A), recall Fig. 3. Indications of boundary layer transition onset can be observed in the figure as the unit Reynolds number was increased to $2.3 \cdot 10^{6} \mathrm{~m}^{-1}$ (condition B), evidenced by the rising trend of the heat flux towards the end of the model. In the laminar boundary layer cases, the frequency spectra measured with the ALTP sensors show distinct peaks. The convection speed of the corresponding flow structures is estimated from the crosscorrelation between the ALTP time signals. For the cases without gas transpiration, the spectral peaks are centered around frequencies corresponding to wavelengths between 2 and 3 times the boundary layer height, estimated by means of CFD computations. LST calculations confirmed the observed peaks to correspond to the most amplified second mode frequencies.

With amplified second modes confirmed to exist downstream of the porous patch, different mass flow rates were applied to assess the effect on the instabilities.

\subsubsection{Test condition $A$ and $5.0 \mathrm{~mm}$ nose radius}

Looking first at the set of cases with the smaller unit Reynolds number (condition A), Fig. 10 shows the frequency spectra measured with ALTP1 as several different mass

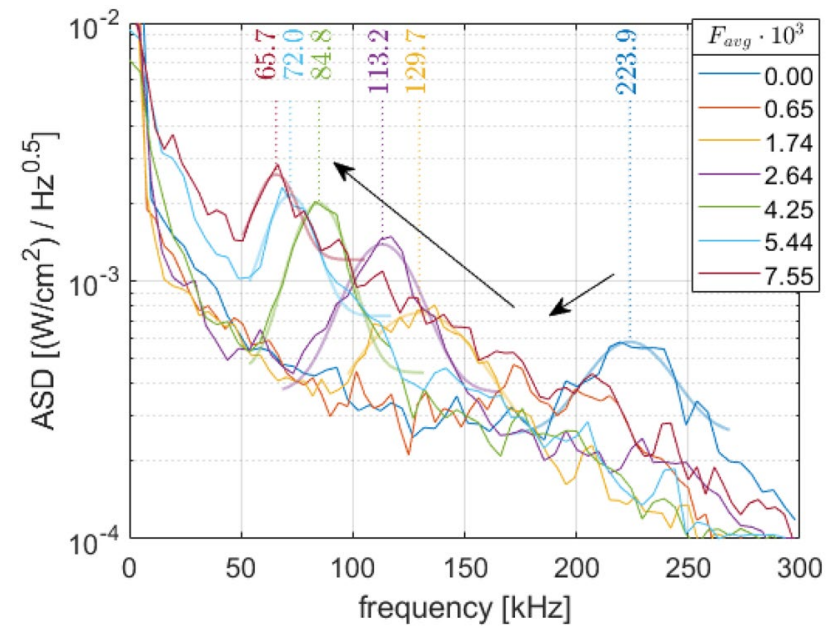

Fig. 10 Heat flux amplitude spectral densities on ALTP1 for $5.0 \mathrm{~mm}$ nose radius, test condition $\mathrm{A}$ and different transpiration rates. Frequencies corresponding to the maximum amplitude of the Gaussian fits are indicated flow rates are transpired into the boundary layer. The solid, semitransparent curves are Gaussian fits to the experimental data, to improve readability. The fits are calculated using a least-square approach on a sufficient number of points to adequately represent the peak shape.

This set of spectra offers some observations which were verified to be consistent in all the investigated laminar cases.

First, it can be immediately seen that mass addition into the boundary layer significantly shifts the peak frequency to lower values. Given the known correlation between second mode wavelength and boundary layer height, a drop in frequency was expected due to the thickening of the boundary layer as a result of mass addition. This effect is quantified later in this section.

Further, it can be seen that as the transpiration rates are gradually increased, the peak amplitude decreases first before increasing again to values comparable to the reference case $\left(F_{\text {avg }}=0\right)$ while the center frequency of the peak drops to around half of its original value. These trends are highlighted with arrows in the figure.

Finally, as the transpiration rates increase, the frequency spectra is gradually pushed toward a turbulent state. This is evidenced by the continuous change in spectrum shape, until an increase in low frequency amplitudes is noticeable for $F_{\text {avg }} \geq 5.44 \cdot 10^{-3}$, and a broadband amplitude increase is seen for $F_{\text {avg }}=7.55 \cdot 10^{-3}$.

The amplitude reduction effect is observed to be stronger in the direct vicinity of the transpiration. Figure 11 shows the spectral distribution further downstream, measured by ALTP3. At this location, the effect of the peak frequency shift to lower values is still very clearly seen, however, the damping of amplitudes is less pronounced than before.

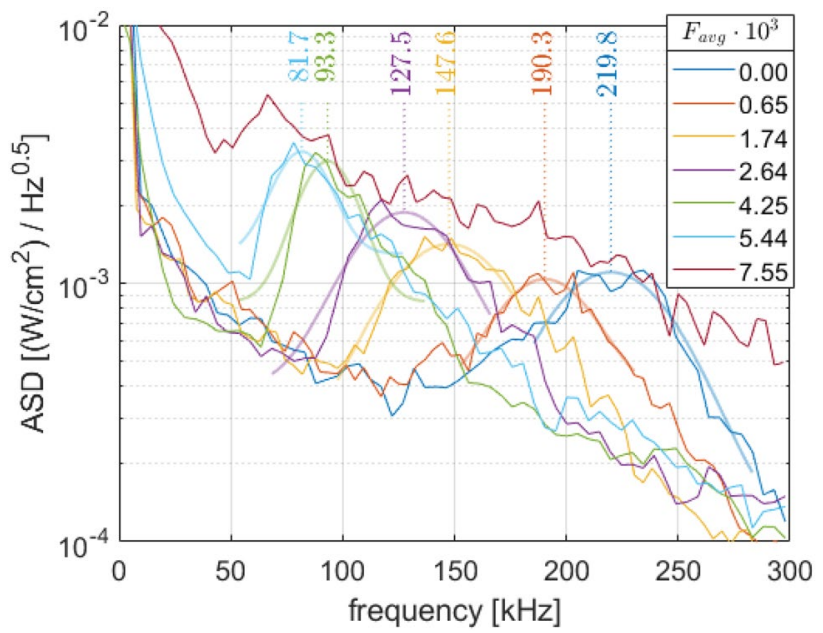

Fig. 11 Heat flux amplitude spectral densities on ALTP3 for $5.0 \mathrm{~mm}$ nose radius, test condition $\mathrm{A}$ and different transpiration rates. Frequencies corresponding to the maximum amplitude of the Gaussian fits are indicated 


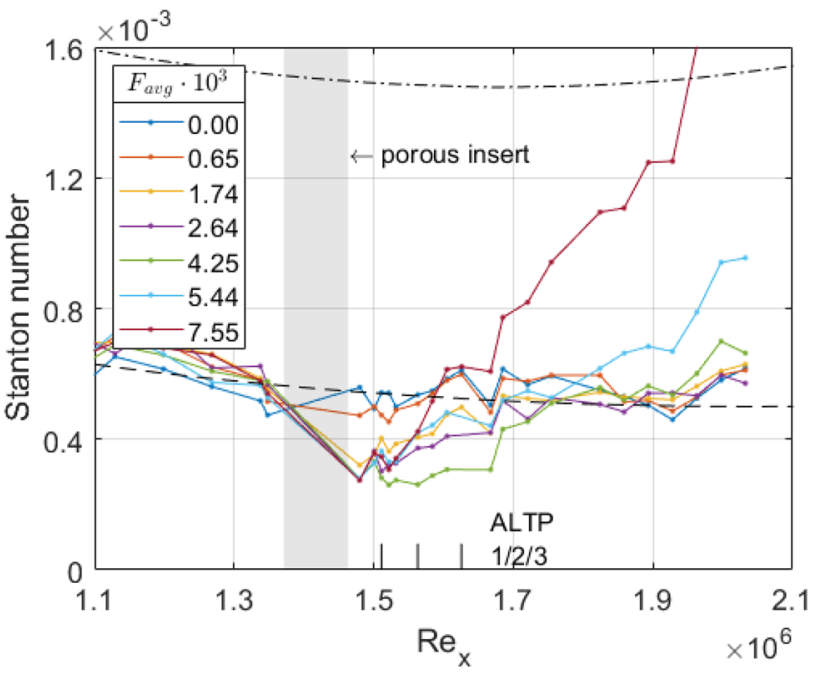

Fig. 12 Stanton number distribution as a function of local Reynolds number along the cone axis for $5.0 \mathrm{~mm}$ nose radius, test condition $\mathrm{A}$ and different transpiration rates

Figure 12 shows the Stanton number distribution along the model for this set of cases. It can be seen that stronger transpiration rates cause a more pronounced cooling effect, but only up to the point where the mass flow rate is still low enough not to cause an early onset of boundary layer transition. In this test condition, the critical value is $F_{\text {avg }}>4.25 \cdot 10^{-3}$. For higher transpiration rates early boundary layer transition causes the cooled region to become smaller.

In Schmidt et al. (2016), the authors reported early onset of boundary layer transition for all the experimentally investigated mass fluxes with their conical-shaped injector. Their lowest transpiration rate for that injector was similar to the critical value observed here, around $F_{\text {avg }}=3.3 \cdot 10^{-3}$. The numerical results in Fedorov et al. (2014) showed that for a conical-shaped injector at slightly lower local Reynolds number than in the present study, the critical $\mathrm{N}$ factor location is pushed upstream for $F_{\text {avg }}=7.0 \cdot 10^{-3}$. For $F_{\text {avg }}=14.0 \cdot 10^{-3}$ the maximum $\mathrm{N}$ factor was reached immediately after the injection. The results in Fig. 12 are in line with these observations. The authors also hypothesized that there may exist a range of mass flow rates capable of creating a stabilized mid-field relaxation region. Although with considerably lower mass flow rate values than in that work, Figs. 10 and 11 indicate the presence of such a region.

Furthermore, in all the cases where early transition onset is observed, namely $F_{\text {avg }} \geq 5.44 \cdot 10^{-3}$, the off-center lines of thermocouples indicated a significantly non-uniform effect of cooling across the cone surface. This is exemplified in Fig. 13, which shows measurements from all four lines of thermocouples (refer to Fig. 2). A clear separation is observed between the measurements taken along the

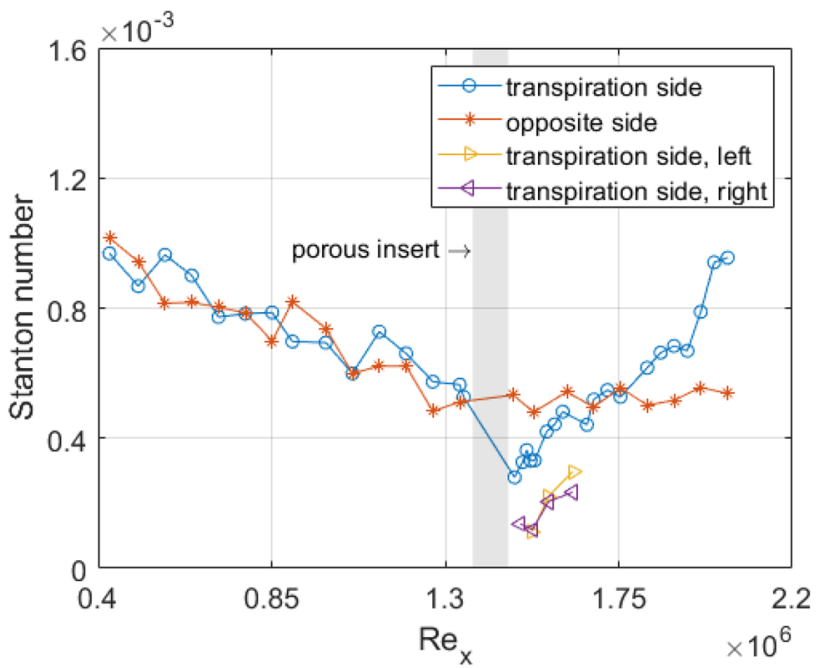

Fig. 13 Stanton number distribution obtained along each of the thermocouple lines for test condition A, nose radius $5.0 \mathrm{~mm}$ and $F_{\text {avg }}=5.44 \cdot 10^{-3}$

center line and off-center lines on the porous patch side. The presence of such strong spanwise variations suggests non-negligible, three-dimensional effects in the boundary layer which might cause early transition. For all cases where transpiration does not cause early transition, these spanwise non-uniformities were not observed.

\subsubsection{Test condition $B$ and $5.0 \mathrm{~mm}$ nose radius}

Figure 3 shows a rise of the heat flux distribution near the end of the model for test condition B. This indicates the onset of transition and provides the possibility of observing potential transition delaying effects caused by the mass addition.

The frequency spectra obtained by ALTP1 and the Stanton number distributions along the cone for this set of cases are shown in Figs. 14 and 15, respectively.

In Fig. 14, it can be seen that the second modes are stronger than in the previous test condition, as would be expected due to the higher unit Reynolds number. Most importantly, the trends observed in the previous cases are present again. Moderate transpiration rates are capable of damping the instability amplitudes. Further increasing the rates causes the peak amplitudes to increase again. Gradually, the boundary layer state moves to turbulent with increasing low frequency amplitudes. For $F_{\text {avg }}=5.46 \cdot 10^{-3}$ the spectrum shows the broadband amplitude increase typical of fully turbulent boundary layers.

Figure 15 shows that the critical mass flow rate above which boundary layer transition is triggered is lower in this test condition, compared to the condition with smaller unit Reynolds number, namely $F_{\text {avg }}>1.60 \cdot 10^{-3}$. Again, 


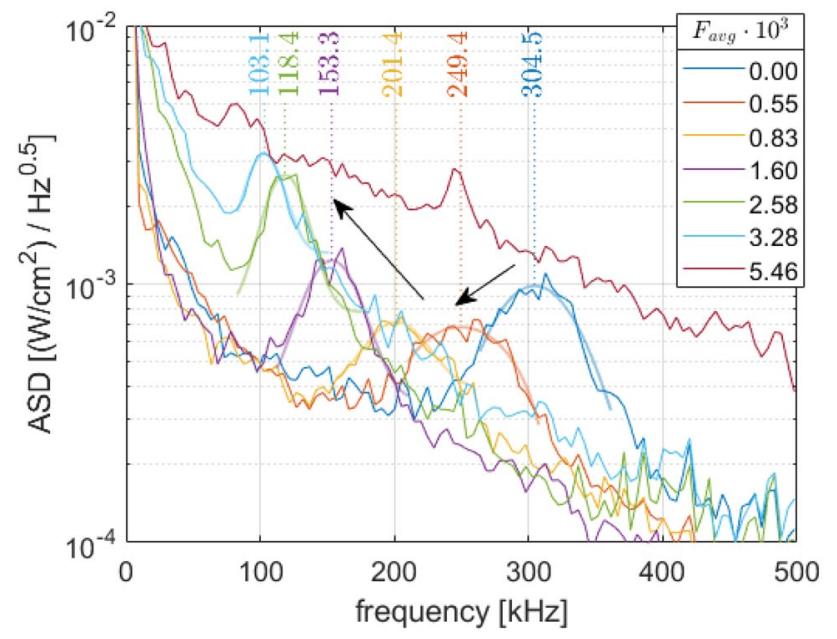

Fig. 14 Heat flux amplitude spectral densities on ALTP1 for $5.0 \mathrm{~mm}$ nose radius, test condition $\mathrm{B}$ and different transpiration rates. Frequencies corresponding to the maximum amplitude of the Gaussian fits are indicated

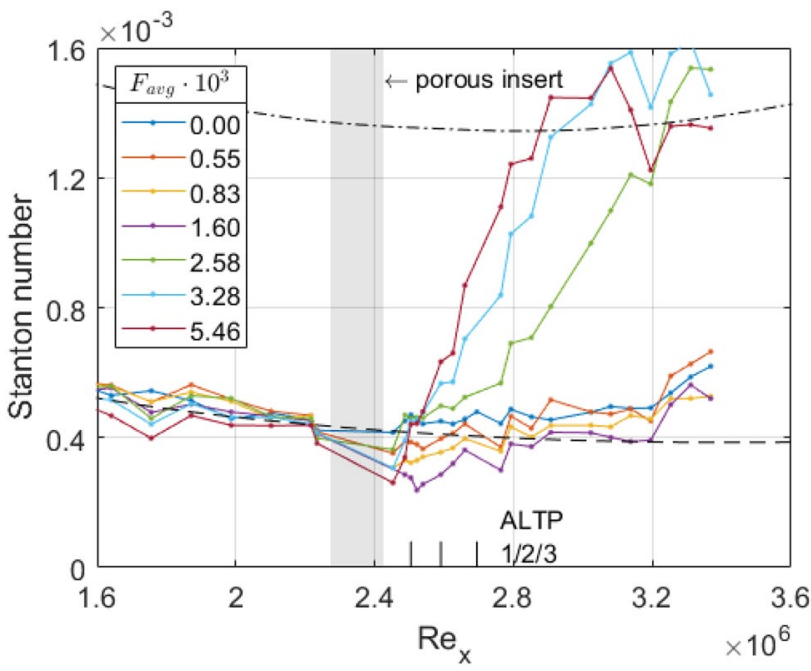

Fig. 15 Stanton number distribution as a function of local Reynolds number along the cone axis for $5.0 \mathrm{~mm}$ nose radius, test condition $\mathrm{B}$ and different transpiration rates

non-uniformities were observed in the flow downstream of the transpiration location for these rates, similar to the example shown in Fig. 13. For all transpiration rates where early transition does not occur, the heat-flux readings were uniform in the lateral direction.

Miró Miró et al. (2019) investigated a range of similar transpiration rates on a cone at similar local Reynolds and Mach numbers (refer to Fig. 1). In their numerical analysis, neglecting the porous wall effects, they concluded that the investigated mass flow rates cause early boundary layer transition onset, based on a critical N-factor of 5.9. Furthermore, experiments were performed and confirmed the numerical observations. This is in opposition to what is seen here. A possible explanation for this observation is the sensitivity of the effects of transpiration to its location with respect to the critical $\mathrm{N}$-factor, as mentioned in Wartemann et al. (2019b). The N-factor envelope which results from a localized mass addition presents a limited region of stabilization close to the transpiration location. Further downstream, the $\mathrm{N}$-factor envelope rises steeply as shown in Fedorov et al. (2014). In Miró Miró et al. (2019), transpiration was realised far upstream of the critical $\mathrm{N}$-factor location. In HEG, the critical $\mathrm{N}$-factor has been verified to be around 6.0 (Wagner et al. 2012). Wartemann et al. (2019b) have verified that for similar test cases without transpiration, this critical $\mathrm{N}$-factor is reached shortly downstream of the transpiration location, hence allowing the transpiration to be beneficial with respect to transition delay.

Regarding the transpiration rates in Fig. 15 for which mass addition does not cause early transition, i.e. $F_{\text {avg }} \leq 1.60 \cdot 10^{-3}$, the Stanton numbers are observed to consistently follow separate trends. However, no conclusion on the effect of transpiration on the transition process can be drawn.

Figure 16 shows the numerical frequency spectra at the location corresponding to ALTP1 on the model. The corresponding experimentally obtained spectra is shown for comparison, repeated from Fig. 14.

In the LST results with mass addition (red dashed-dot line in Fig. 16), two groups of frequencies occur. One group of higher frequencies starts to get damped and die out, whereas a second family of lower frequencies gets strongly excited, but first has to grow in downstream direction to reach high $\mathrm{N}$-values. This results in the two visible peaks for the LST test case with transpiration. In

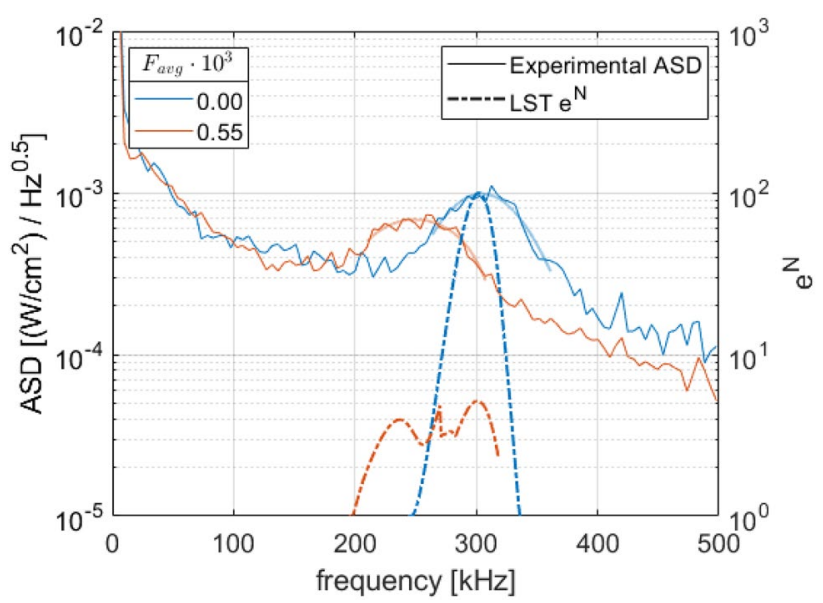

Fig. 16 LST results (right y-axis) and measured heat flux spectra (left $\mathrm{y}$-axis) on ALTP1 for $5.0 \mathrm{~mm}$ nose radius, test condition B, with and without mass addition 
Wartemann et al. (2019a), a good agreement was demonstrated when applying similar mass fluxes as referred to in Fig. 16, for the same geometry and free-stream conditions. The observed differences between the measured/ calculated frequency of the maxima were less than $5 \%$ and an acceptable agreement $(<13 \%)$ was shown between the measured/calculated growth rates between the locations of the ALTP sensor positions. These growth rate comparisons were performed among the three ALTP locations within any given case, and similar results are obtained when this methodology is applied for the cases shown here.

Figure 16 uses a different approach, plotting the experimental amplitudes together with the numerical results for a single sensor position (namely, ALTP1), but with different transpiration rates. It shows that the LST calculations are capable of capturing the mass addition influence with good qualitative agreement, regarding the shift of the most unstable frequencies and the damping trend of the second modes. A quantitative comparison, however, does not provide reliable estimates, with the LST largely overestimating the damping effect of mass injection. A possible explanation is that the used linear stability analysis underpredicts the increase of the low frequency group due to possibly present non-linear effects.

Despite this poor quantitative agreement, Fig. 16 confirms the frequency peaks observed experimentally to correspond to second mode instabilities, for the cases of zero and low transpiration rates. Stability computations with higher transpiration mass flow rates were not possible, due to limitations of LST dealing with strong boundary layer disturbances.

To verify whether the lower frequency peaks observed for stronger transpiration rates still correspond to second mode instabilities, CFD computations were conducted for selected experimental test cases at the specific test conditions covering the following mass flow rates $F_{\text {avg }}=0.00$, $0.55 \cdot 10^{-3}, 1.60 \cdot 10^{-3}$ and $2.58 \cdot 10^{-3}$. Figure 17 shows the extracted boundary layer velocity profiles at the position corresponding to ALTP1. The color code is kept from Fig. 14. The boundary layer heights for each case based on $99 \%$ of the edge velocity, $\delta_{u_{99}}$, are highlighted.

It can be seen that the frequency drop observed in Fig. 14 does not scale with boundary layer thickness. Nonetheless, the changes induced in the boundary layer by transpiration are not restricted to the velocity profiles. Temperature profiles also change and so does the local speed of sound.

The second mode instabilities are disturbances in the form of acoustic waves which are trapped inside the boundary layer. Therefore, a region of locally supersonic flow relative to the phase speed of the instability wave must exist in the boundary layer (Mack 1990). Equation (6) defines the convective Mach number $M_{c}$ as the Mach number component

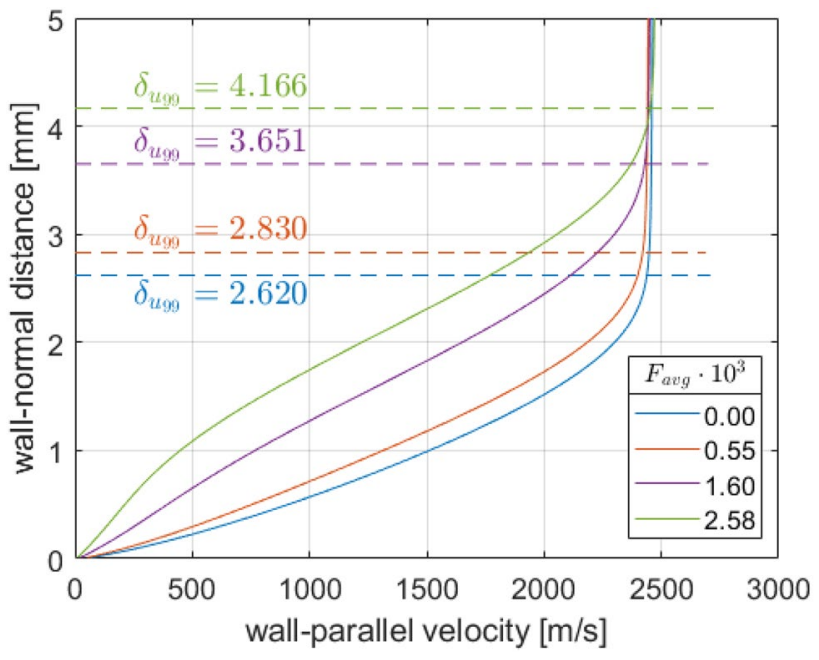

Fig. 17 Boundary layer velocity profiles at the position corresponding to ALTP1 for $5.0 \mathrm{~mm}$ nose radius, test condition B, with and without mass addition. Boundary layer heights $\delta_{u_{99}}$ are indicated for each case

of the flow in the direction of propagation of the instability wave and relative to its phase speed $c$ :

$M_{c}(y)=\frac{c-u(y)}{a(y)}$

where $y$ is the wall-normal coordinate, $u(y)$ is the wall-parallel velocity and $a(y)$ is the local speed of sound.

The wall-normal distance where $M_{c}=1$ defines the position of the relative sonic line for each case, i.e. the height where the disturbance phase speed becomes sonic with respect to the local mean flow. According to Morkovin (1987) the second mode acoustic disturbances travel along Mach lines and are reflected at the wall and at the relative sonic line of the boundary layer. Thus, to evaluate the frequency reductions observed in the present test cases with transpiration it is more appropriate to compare the sonic line displacement, rather than the boundary layer thickness.

The convective speed $c$ in Eq. (6) is obtained for each case from the cross-correlation of the time resolved signals recorded by the ALTPs. The acceptable lag is limited to a range of values corresponding to between $75 \%$ and $100 \%$ of the boundary layer edge velocity, given by the CFD solution.

Figure 18 shows the obtained convective Mach number profiles, highlighting the relative sonic line heights, $\delta_{s}$.

Indeed, the frequencies in Fig. 14 scale very closely with the relative sonic line heights in Fig. 18. Table 3 shows the calculated frequency and height ratios and relative differences for all three ALTPs for the cases analyzed in Fig. 18. These results offer evidence that the frequency peaks refer to second modes even in the cases with large mass flow rates and thus stronger frequency shifts. 


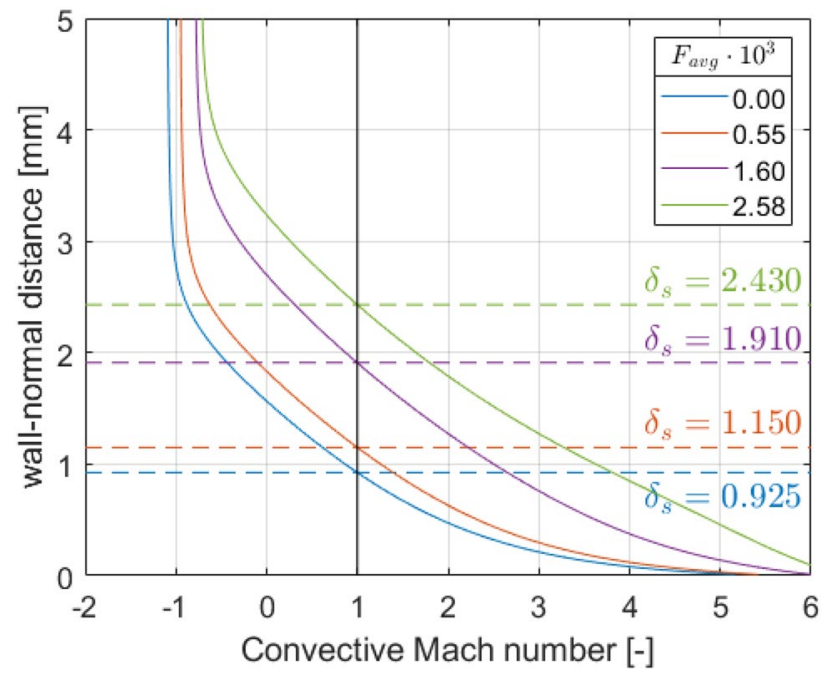

Fig. 18 Convective Mach number profiles at the position corresponding to ALTP1 for $5.0 \mathrm{~mm}$ nose radius, test condition B, with and without mass addition. The relative sonic line heights $\delta_{s}$ are indicated as dashed lines

Table 3 Ratios of measured frequency $f$, ratios of calculated sonic line heights $\delta_{s}$, and the relative difference between both. Test condition $\mathrm{B}, 5.0 \mathrm{~mm}$ nose radius and three different transpiration mass flow rates. The subscript $r$ refers to the reference case, $F_{\text {avg }}=0$

\begin{tabular}{lllll}
\hline & & ALTP1 & ALTP2 & ALTP3 \\
\hline$F_{\text {avg }}=0.55 \cdot 10^{-3}$ & $f / f_{r}$ & 0.8190 & 0.8228 & 0.8318 \\
& $\left(\delta_{s} / \delta_{s_{r}}\right)^{-1}$ & 0.8043 & 0.8274 & 0.8514 \\
& Difference $(\%)$ & 1.79 & 0.56 & 2.36 \\
$F_{\text {avg }}=1.60 \cdot 10^{-3}$ & $f / f_{r}$ & 0.5034 & 0.5200 & 0.5597 \\
& $\left(\delta_{s} / \delta_{s_{r}}\right)^{-1}$ & 0.4843 & 0.5180 & 0.5543 \\
& Difference $(\%)$ & 3.79 & 0.38 & 0.96 \\
$F_{\text {avg }}=2.58 \cdot 10^{-3}$ & $f / f_{r}$ & 0.3880 & 0.3980 & 0.4424 \\
& $\left(\delta_{s} / \delta_{s_{r}}\right)^{-1}$ & 0.3807 & 0.4048 & 0.4385 \\
& Difference $(\%)$ & 1.88 & 1.71 & 0.88 \\
\hline
\end{tabular}

Finally, it is further interesting to notice that also for this test condition the progressive damping of amplitudes in Fig. 14 with mass addition is limited to a frequency drop of around $50 \%$ of the reference case. This ratio is similar to what was seen at condition A, even though the most amplified frequencies are different. This suggests that there is an optimal perturbation of the boundary layer to provoke a detuning with respect to the most amplified second mode frequencies, limited to a reduction of the most unstable frequency to approximately $50 \%$ of its undisturbed value.

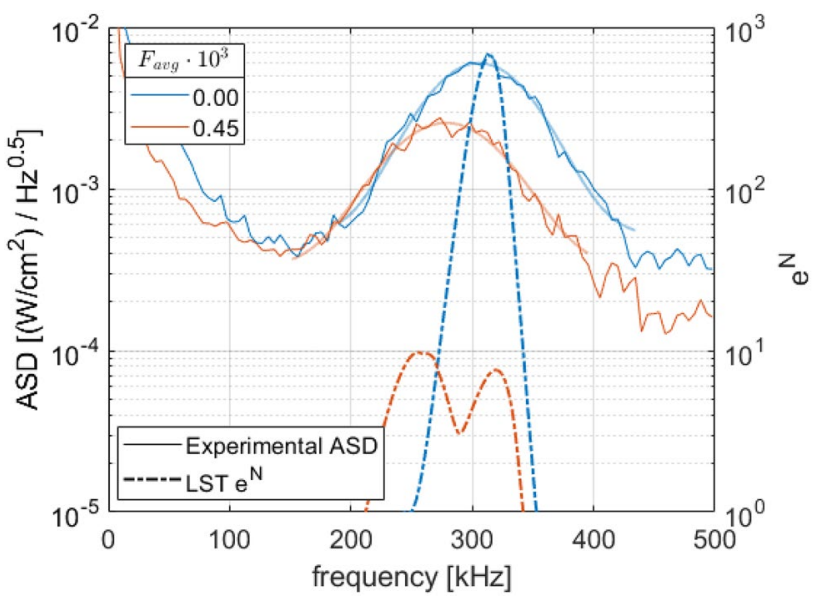

Fig. 19 LST results (right-hand axis) and measured heat flux spectra (left-hand axis) at ALTP1 for $2.5 \mathrm{~mm}$ nose radius, test condition B, with and without mass addition

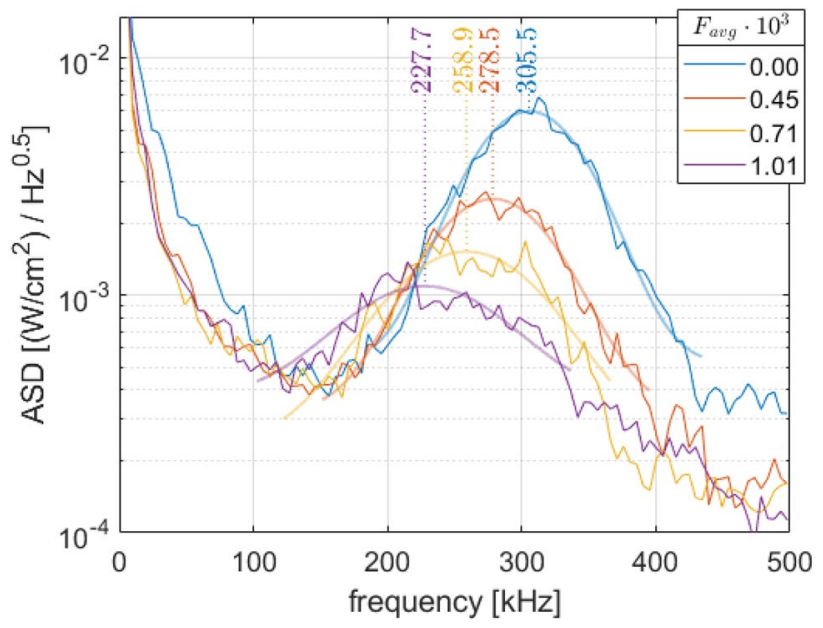

Fig. 20 Heat flux amplitude spectral densities at ALTP1 for $2.5 \mathrm{~mm}$ nose radius, test condition $\mathrm{B}$ and different transpiration rates. Frequencies corresponding to the maximum amplitude of the Gaussian fits are indicated

\subsubsection{Test condition $B$ and $2.5 \mathrm{~mm}$ nose radius}

A third laminar boundary layer set of cases is investigated, using test condition B (unit Reynolds number $2.3 \cdot 10^{6} \mathrm{~m}^{-1}$ ), with a sharper nose radius of $2.5 \mathrm{~mm}$. In these conditions, the boundary layer is laminar over the porous insert, but clearly starts transitioning shortly downstream of it, see Fig. 3.

Figure 19 shows the LST calculation for the cases with no transpiration and the lowest investigated transpiration value. Figure 20 shows the frequency spectra obtained at ALTP1 for the complete set of investigated transpiration mass flow rates. The second mode amplitudes are higher compared to 
Table 4 Ratios of measured second mode frequency $f$, ratios of calculated relative sonic line heights $\delta_{s}$, and the relative difference between both. Test condition B, $5.0 \mathrm{~mm}$ nose radius. The subscript $r$ refers to the reference case, $F_{\text {avg }}=0$

\begin{tabular}{lllll}
\hline & & ALTP1 & ALTP2 & ALTP3 \\
\hline$F_{\text {avg }}=0.45 \cdot 10^{-3}$ & $f / f_{r}$ & 0.9116 & 0.9130 & 0.9310 \\
& $\left(\delta_{s} / \delta_{s_{r}}\right)^{-1}$ & 0.8750 & 0.8981 & 0.9122 \\
& Difference $(\%)$ & 4.01 & 1.63 & 2.02 \\
\hline
\end{tabular}

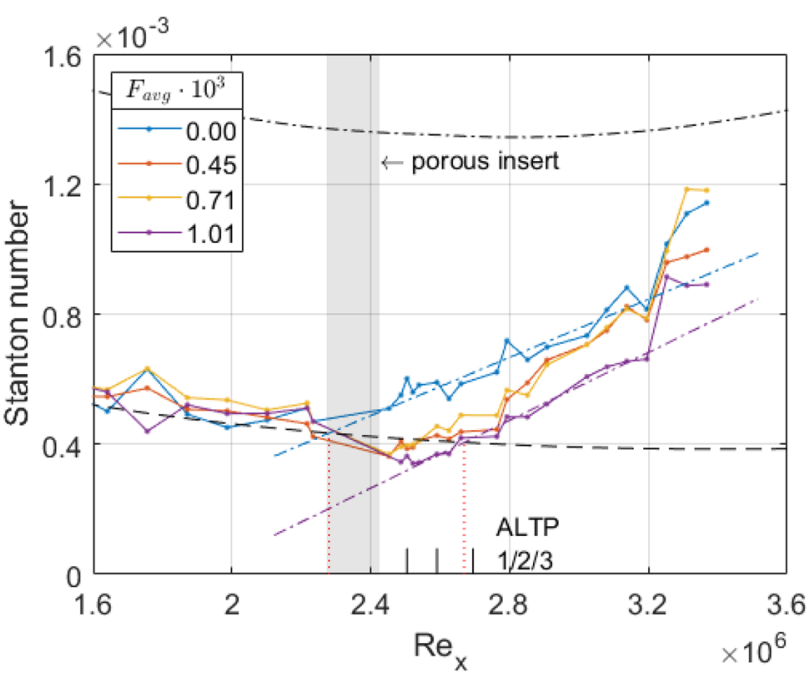

Fig. 21 Stanton number distribution as a function of local Reynolds number along the cone axis for $2.5 \mathrm{~mm}$ nose radius, test condition $\mathrm{B}$ and different transpiration rates. Linear fits for the rising portions of the curves for no transpiration and the highest transpiration rate are shown

the previous sets of cases, which is expected since the transition onset takes place closer downstream of the sensors. The damping of the second mode amplitudes is clearly seen, as well as the shift in the frequency towards lower values with increasing mass flow rates. The evaluated LST cases confirm the frequency peaks to correspond to second modes, and show a reasonable qualitative agreement with the corresponding experimental results.

As in the previous subsection, Table 4 presents the relative frequency drop due to transpiration and the corresponding change of the relative sonic line height above the surface based on CFD computations, for $F_{\text {avg }}=0.45 \cdot 10^{-3}$. Although a smaller sample of results is evaluated, a good agreement is found.

The reversal of the damping trend that was observed in Figs. 10 and 14 is not seen in Fig. 20, as the maximum investigated transpiration mass flow rate is lower. However, the resulting effect of this recurring damping of second modes can finally be seen in Fig. 21, where the Stanton number distribution is shown. In addition to the expected cooling effect shortly after the porous insert as a consequence of cold gas transpiration, it can be observed that boundary layer transition is consistently shifted downstream.

The methodology described in Sect. 4.3 is used to quantify the delay of the boundary layer transition onset. Figure 21 shows a linear fit through the rising portions of the curves with no mass addition and with $F_{\text {avg }}=1.01 \cdot 10^{-3}$. Near the end of the model the transition process seems to get accelerated for all cases, which needs to be studied further. However, estimating the transition onset by means of the methodology above, a delay of approximately $17 \%$ is observed for $F_{\text {avg }}=1.01 \cdot 10^{-3}$.

The schlieren images for this set of cases revealed strong and numerous second mode wave packets. Convection speed determination following Petervari (2014) confirmed the values calculated through the cross-correlation of the ALTP signals to within $1 \%$. The schlieren images are used to perform a wavelet analysis, see Bentley and McDonnell (1994), on the second mode structures, following Benjamin (2017). Multiple sequences of images containing clear second mode wave packets are selected, such as the one shown in Fig. 22. Morlet wavelet transforms of the image sequences containing second mode waves are calculated. The schlieren visualization window is divided into sections of 100 pixels width, corresponding to approximately $3 \lambda$. In each section, the maximum wavelet coefficient and its frequency are determined in the upper half of the boundary layer. These operations yield estimates for second mode frequencies around the porous patch, which are shown in Fig. 23. The test case without gas transpiration (blue line) provides a reference for the undisturbed second mode frequency evolution along the cone surface. The lines corresponding to the cases with mass addition (red and yellow) show an increased slope with lower frequencies as a result of the forced boundary layer profile changes. The observable reductions corroborate the hypothesis of detuning the boundary layer with respect to the most unstable second mode frequency as a result of transpiration into the boundary layer.

Figures 24 and 25 show contour plots of wavelet transforms for the case without transpiration and the case with $F_{\text {avg }}=0.71 \cdot 10^{-3}$, respectively. The applied wavelet frequency range is the same for both cases, namely 200 to 400 $\mathrm{kHz}$, including the majority of the second modes energy as seen in Fig. 20. The color scale is the same for both figures, to allow a direct comparison of the instability amplitudes. In each of these figures, an observed second mode wave packet is depicted.

In Fig. 24, the wave packet can be seen convecting and growing along the entire observed field of view with little change in the considered frequency range. In Fig. 25, 
Fig. 22 Schlieren images of a second mode wave packet traveling along the surface of a cone with $2.5 \mathrm{~mm}$ nose radius, obtained with test condition B. $\Delta t=5.89 \mu s$
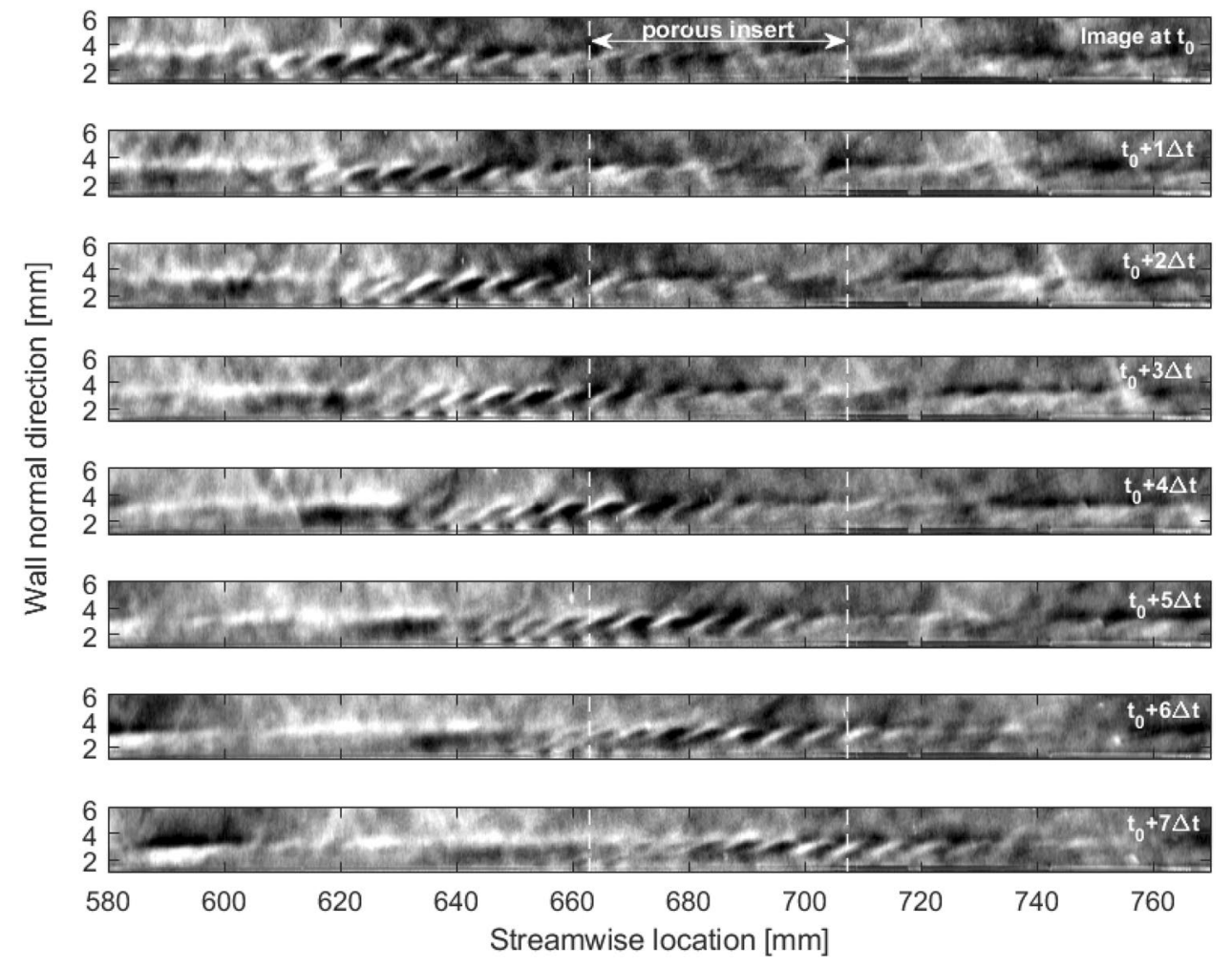

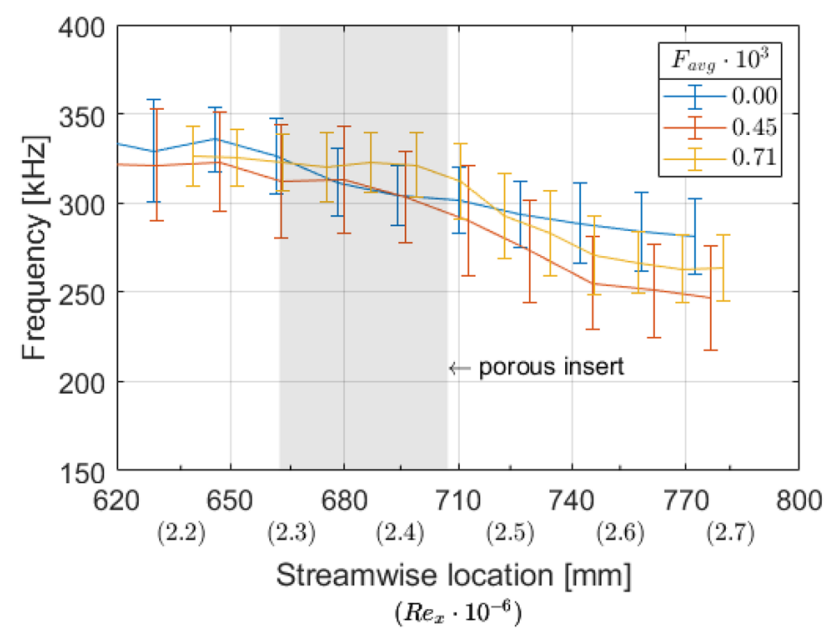

Fig. 23 Second mode frequencies obtained with wavelet analyses from schlieren images, obtained on the cone with $2.5 \mathrm{~mm}$ nose radius and test condition $\mathrm{B}$

the mass transpiration through the porous insert is seen to significantly reduce the amplitude of the second mode wave packet. Thus, independently from surface mounted transducers, the wavelet analysis confirms the aforementioned damping effect on the second mode instability.

\section{Conclusions}

In this work, the effects of nitrogen transpiration through a porous $\mathrm{C} / \mathrm{C}$ insert into a hypersonic boundary layer were experimentally investigated with respect to its stability.

Fifteen different transpiration mass flow rates were investigated in laminar boundary layers with three distinct stages of second mode instability growth. Frequency spectra downstream of the transpiration region exhibited amplitude peaks along a wide range of frequencies across the investigated cases. Through a combination of linear stability theory computations and analysis of the boundary layer profiles obtained by means of CFD, these peaks were confirmed to be second modes. Their measured frequencies were verified to scale with the height of the relative sonic line in the boundary layer.

In all the analyzed test cases, transpiration rates below around $0.1 \%$ of the equivalent boundary layer edge mass flow rate were capable of locally damping the second mode instabilities through a reduction of the most unstable frequency. Heat flux spectra and wavelet analysis performed on high speed schlieren images independently confirmed these effects. Increasing the mass flow rates caused amplitude peaks to appear at smaller frequencies. Further increases resulted in the low frequency amplitudes to become stronger and finally immediate boundary layer transition. In the latter case, strong spanwise variations in Stanton number were verified downstream of the transpiration location, indicating 
Fig. 24 Wavelet transform of a sequence of schlieren images obtained for a cone with 2.5 $\mathrm{mm}$ nose radius, test condition $\mathrm{B}$ and no mass transpiration. An undisturbed second mode wave packet is shown. $\Delta t=5.89 \mu \mathrm{s}$

Fig. 25 Wavelet transform of a sequence of schlieren images obtained for a cone with $2.5 \mathrm{~mm}$ nose radius, test condition $\mathrm{B}$ and transpiration mass flow rate $F_{\text {avg }}=0.71 \cdot 10^{-3}$. A second mode wave packet experiencing damping across the transpiration location is shown. $\Delta t=5.89 \mu \mathrm{s}$
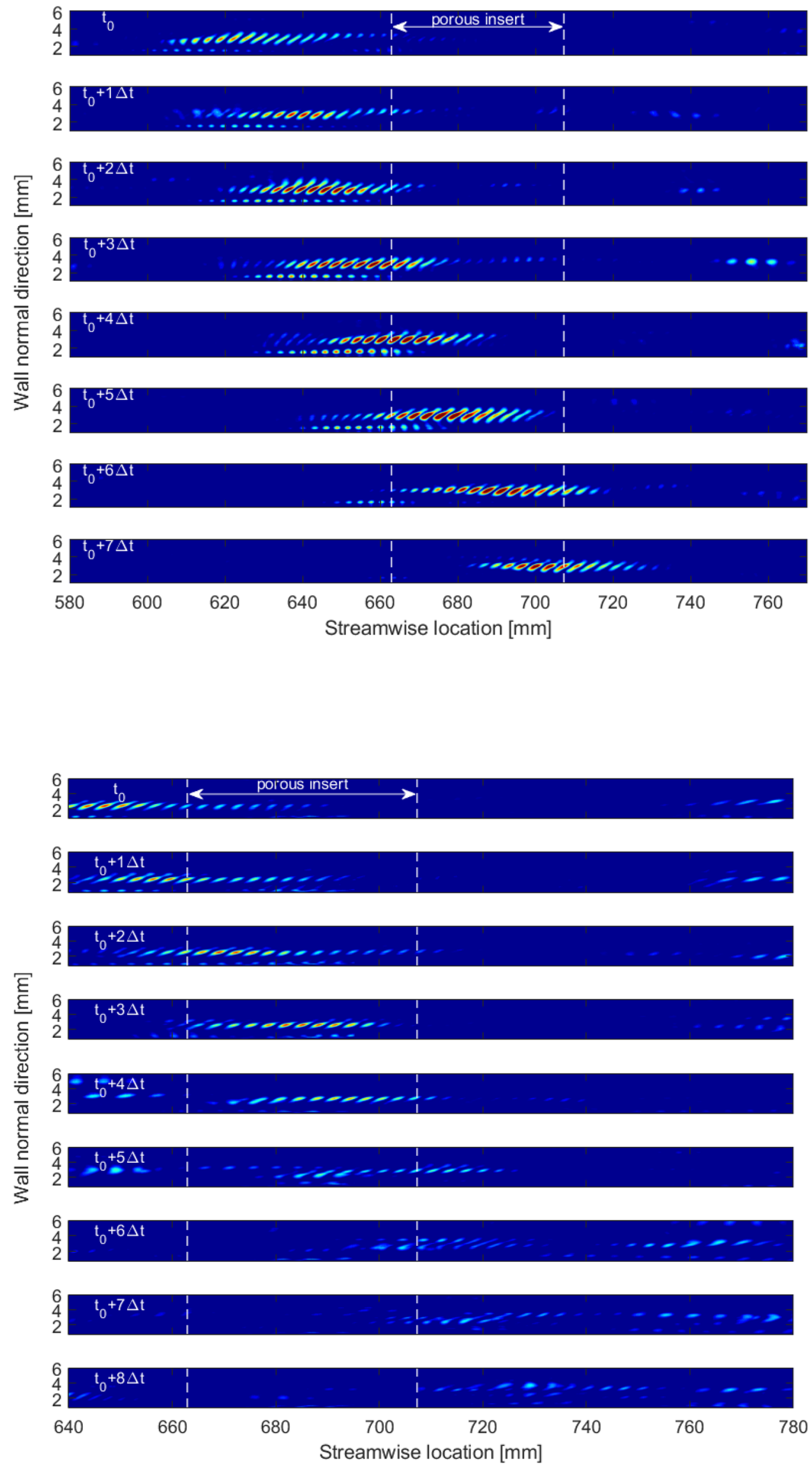
three-dimensional effects which could be responsible for the early transition onset. For all cases where transpiration did not cause early transition, no spanwise non-uniformities were observed.

It was found that at lower unit Reynolds number, larger mass flow rates were acceptable before causing early transition onset. The observed critical values were $F_{\text {avg }}>4.25 \cdot 10^{-3}$ for $\operatorname{Re}_{m}=1.4 \cdot 10^{6} \mathrm{~m}^{-1}$ and $F_{\text {avg }}>1.60 \cdot 10^{-3}$ for $\operatorname{Re}_{m}=2.3 \cdot 10^{6} \mathrm{~m}^{-1}$. Thus, although the investigated transpiration rates were normalized with respect to the equivalent boundary layer edge mass flow rate, the effect of a given transpiration rate was not independent of the free-stream conditions.

Nevertheless, the effect of damping of second mode amplitudes was only observed until the most amplified frequency dropped to around $50 \%$ of the original value. This factor was common for the two different unit Reynolds numbers with laminar boundary layer. This indicates the existence of an optimal perturbation of the boundary layer to obtain damping of second modes. For $\operatorname{Re}_{m}=1.4 \cdot 10^{6} \mathrm{~m}^{-1}$ a transpiration rate of $F_{\text {avg }}=0.65 \cdot 10^{-3}$ was observed to dampen second mode amplitude. With $\mathrm{Re}_{m}=2.3 \cdot 10^{6} \mathrm{~m}^{-1}$, rates up to $F_{\text {avg }}=1.01 \cdot 10^{-3}$ were verified to yield the same effect.

In the test cases of $\operatorname{Re}_{m}=2.3 \cdot 10^{6} \mathrm{~m}^{-1}$ and $2.5 \mathrm{~mm}$ nose radius, mass addition was realized shortly upstream of the boundary layer transition onset. Experimentally observed second modes were strong and numerous in this position, and previous LST analyses had indicated it to be close to the critical $\mathrm{N}$-factor location. In this scenario, the damping of second mode amplitude through carefully adjusted transpiration rates was verified to produce a transition delay of approximately $17 \%$.

Acknowledgements Open Access funding provided by Projekt DEAL. The authors wish to acknowledge the assistance of the HEG team, in particular Ingo Schwendtke, Uwe Frenzel, Jan Martinez Schramm and Damian Friedl.

Open Access This article is licensed under a Creative Commons Attribution 4.0 International License, which permits use, sharing, adaptation, distribution and reproduction in any medium or format, as long as you give appropriate credit to the original author(s) and the source, provide a link to the Creative Commons licence, and indicate if changes were made. The images or other third party material in this article are included in the article's Creative Commons licence, unless indicated otherwise in a credit line to the material. If material is not included in the article's Creative Commons licence and your intended use is not permitted by statutory regulation or exceeds the permitted use, you will need to obtain permission directly from the copyright holder. To view a copy of this licence, visit http://creativecommons.org/licenses/by/4.0/.

\section{References}

Benjamin L (2017) Investigation of instability growth in a hypersonic boundary layer using schlieren visualization. Master's thesis, Delft University of Technology

Bentley P, McDonnell J (1994) Wavelet transforms: an introduction. Electron Commun Eng J 6(4):175-186. https://doi.org/10.1049/ ecej:19940401

Bottin B (1999) Aerothermodynamic model of an inductively-coupled plasma wind tunnel: Numerical and experimental determination of the facility performance. $\mathrm{PhD}$ thesis, Von Karman Institute for Fluid Dynamics

Dittert C, Selzer M, Böhrk H (2015) Characterization of the flow field of anisotropic porous cones with different wall thickness. In: 20th AIAA International Space Planes and Hypersonic Systems and Technologies Conference, https://doi.org/10.2514/6.2015-3661, AIAA 2015-3661

DLR (2018) The High Enthalpy Shock Tunnel Göttingen of the German Aerospace Center (DLR). J Large Scale Res Facilities 4:A133 https://doi.org/10.17815/jlsrf-4-168

Dunavant JC, Everhart PE (1969) Exploratory heat-transfer measurements at Mach 10 on a $7.5^{\circ}$ total-angle cone downstream of a region of air and helium transpiration cooling. Technical Report NASA TN D-5554, NASA

Eitelberg G (1994) First results of calibration and use of the HEG. In: 18th AIAA Aerospace Ground Testing Conference. https:// doi.org/10.2514/6.1994-2525, AIAA 94-2525

Eitelberg G, McIntyre TJ, Beck WH, Lacey J (1992) The High Enthalpy Shock Tunnel in Göttigen. In: 17th AIAA Aerospace Ground Testing Conference. https://doi.org/10.2514/6.19923942, AIAA 92-3942

Esser B (1991) Die Zustandsgrößen im Stoßwellenkanal als Ergebnisse eines exakten Riemannlösers. PhD thesis, TH Aachen

Fedorov AV, Soudakov VG, Leyva IA (2014) Stability analysis of high-speed boundary-layer flow with gas injection. In: 7th AIAA Theoretical Fluid Mechanics Conference, Atlanta. https ://doi.org/10.2514/6.2014-2498, AIAA 2014-2498

Fujii K, Hornung HG (2003) Experimental investigation of highenthalpy effects on attachment-line boundary-layer transition. AIAA J 41(7):1282-1291. https://doi.org/10.2514/2.2096

Gülhan A, Braun S (2011) An experimental study on the efficiency of transpiration cooling in laminar and turbulent hypersonic flows. J Fluid Mech 50:509-525. https://doi.org/10.1007/s0034 8-010-0945-6

Hannemann V (2006) Numerical investigation of an effusion cooled thermal protection material. In: Fourth International Conference on Computational Fluid Dynamics, https://elib.dlr.de/43762/

Hein S, Bertolotti FP, Simen M, Hanifi A, Henningson D (1994) Linear nonlocal instability analysis - the linear NOLOT code. Technical Report IB-223-94 A56, DLR

Jewell JS, Leyva IA, Parziale NJ, Shepherd JE (2012) Effect of gas injection on transition in hypervelocity boundary layers. In: 28th International Symposium on Shock Waves, pp 735-740. https://doi.org/10.1007/978-3-642-25688-2_111

Johnson HB, Gronvall JE, Candler GV (2009) Reacting hypersonic boundary layer stability with blowing and suction. In: 47th AIAA Aerospace Sciences Meeting Including the New Horizons Forum and Aerospace Exposition, Orlando. https://doi. org/10.2514/6.2009-938, AIAA 2009-938

Laganelli AL, Fogarolli RP, Martelucci A (1975) The effects of mass transfer and angle of attack on hypersonic turbulent boundary layer characteristics. Technical Report AFFDL-TR-75-35, AFFDL

Li F, Choudhari M, Chang CL, White J (2011) Boundary layer transition over blunt hypersonic vehicles including effects 
of ablation-induced out-gassing. In: 6th AIAA Theoretical Fluid Mechanics Conference, Honolulu, Hawaii. https://doi. org/10.2514/6.2011-3303, AIAA 2011-3303

Li F, Choudhari M, Chang CL, White J (2013) Effects of injection on the instability of boundary layers over hypersonic configurations. AIP Phys Fluids 25(10):104107. https://doi. org/10.1063/1.4825038

Mack LM (1990) On the inviscid acoustic-mode instability of supersonic shear flows. Theor Comput Fluid Dyn 2:97-123. https:// doi.org/10.1007/BF00272137

Mack A, Hannemann V (2002) Validation of the unstructured DLRTAU-Code for hypersonic flows. In: 32nd AIAA Fluid Dynamics Conference and Exhibit, St. Louis, Missouri. https://doi. org/10.2514/6.2002-3111, AIAA 2002-3111

Martelucci A (1972) Effects of mass transfer on hypersonic turbulent boundary-layer properties. AIAA J 10(2):181-187. https://doi. org/10.2514/3.6557

Marvin JG, Akin CM (1970) Combined effects of mass addition and nose bluntness of boundary-layer transition. AIAA J 8(5):857863. https://doi.org/10.2514/3.5778

Miró Miró F, Dehairs P, Pinna F, Gkolia M, Masutti D, Regert T, Chazot O (2019) Effect of wall blowing on hypersonic boundary-layer transition. AIAA J 57(4):1567-1578. https://doi.org/10.2514/1. j057604

Morkovin MV (1987) Transition at hypersonic speeds. Tech. Rep. ICASE Interim Report 1, NASA Contractor Rep. 178315

Pappas CC, Okuno AF (1964) Heat-transfer measurement for binary gas laminar boundary layers with high rates of injection. Tech. Rep. NASA TN D-2473, NASA

Petervari R (2014) Quantitative evaluation of high speed schlieren visualizations of hypersonic boundary layer instabilities in HEG. Bachelor thesis, Georg-August-Universität Göttingen

Reimann B, Hannemann V (2010) Numerical investigation of doublecone and cylinder experiments in high enthalpy flows using the DLR TAU code. In: 48th AIAA Aerospace Sciences Meeting Including the New Horizons Forum and Aerospace Exposition. https://doi.org/10.2514/6.2010-1282, AIAA 2010-1282

Schmidt BE, Shepherd JE (2016) Measurements of instability in supersonic flow with injection by time-resolved flow visualization. In: 54th AIAA Aerospace Sciences Meeting, San Diego. https://doi. org/10.2514/6.2016-0599, AIAA 2016-0599

Schmidt BE, Bitter NP, Hornung HG, Shepherd JE (2016) Injection into supersonic boundary-layers. AIAA J 54(1):161-173. https ://doi.org/10.2514/1.J054123

Schneider SP (2010) Hypersonic boundary-layer transition with ablation and blowing. J Spacecr Rockets 47(2):225-237. https://doi. org/10.2514/1.43926
Schwamborn D, Gerhold T, Heinrich R (2006) The DLR TAU-code: Recent applications in research and industry. In: European Conference on Computational Fluid Dynamics ECCOMAS CFD

Van Driest ER (1956) The problem of aerodynamic heating. Aeronautical Engineering Review 15(10):26-41

Wagner A (2014) Passive hypersonic boundary layer transition control using ultrasonically absorptive Carbon-Carbon ceramic with random microstructure. $\mathrm{PhD}$ thesis, Katholieke Universiteit Leuven

Wagner A, Hannemann K, Wartemann V, Tanno H, Ito K (2012) Free piston driven shock tunnel hypersonic boundary layer transition experiments on a cone configuration. In: AVT - Specialists' Meeting on Hypersonic Laminar-Turbulent Transition, RTO, San Diego, California, USA, RTO-MP-AVT-200

Wagner A, Hannemann K, Kuhn M (2014) Ultrasonic absorption characteristics of porous carbon-carbon ceramics with random microstructure for passive hypersonic boundary layer transition control. Exp Fluids 55(6):1750. https://doi.org/10.1007/s0034 8-014-1750-4

Wagnild RM, Candler GV, Leyva IA, Jewell JS, Hornung HG (2010) Carbon Dioxide injection for hypervelocity boundary layer stability. In: 48th AIAA Aerospace Sciences Meeting Including the New Horizons Forum and Aerospace Exposition, Orlando, Florida. https://doi.org/10.2514/6.2010-1244, AIAA 2010-1244

Wartemann V, Camillo GP, Neumann J, Weber A, Wagner A (2019a) Stability analyses of hypersonic, conical flows with transpiration cooling. In: IUTAM symposium on laminar turbulent transition, London, UK

Wartemann V, Camillo GP, Reiter P, Neumann J, Wagner A (2019b) Influence of transpiration cooling on second mode instabilities investigated on hypersonic, conical flows. CEAS Space J 11(3). https://doi.org/10.1007/s12567-019-00249-9, print ISSN 18682502 Online ISSN 1868-2510

Wartemann V, Wagner A, Wagnild R, Pinna F, Miró Miró F, Tanno H, Johnson H (2019c) High enthalpy effects on hypersonic boundary layer transition. J Spacecr Rockets 56(2):347-356. https://doi. org/10.2514/1.A34281

Publisher's Note Springer Nature remains neutral with regard to jurisdictional claims in published maps and institutional affiliations. 